\title{
Novel Bimetallic Tin-Manganese Oxides/Carbon Nanotube Nanocomposite and Their Charge Storage Properties
}

\author{
(Date received: 20.09.2013/Date accepted: 05.05.2014) \\ Ir. Dr Ng Kok Chiang"1, Ms. Siew Shee Lim² $^{2}$, Dr Chuang Peng ${ }^{3}$ \\ ${ }^{1}$ R\&D Centre, Leong Hing Sdn. Bhd., No.1, Jalan P4/7, Seksyen 4, Bandar Teknologi Kajang, \\ 43500, Semenyih, Selangor, Malaysia \\ ${ }^{2}$ Department of Chemical and Environmental Engineering, Faculty of Engineering, University of Nottingham Malaysia Campus, \\ Jalan Broga, 43500 Semenyih, Selangor, Malaysia \\ ${ }^{3}$ Renewable Energy Research Group, College of Engineering, Mathematics and Physical Sciences, University of Exeter, \\ Cornwall Campus, Penryn, Cornwall, UK TR 10 9EZ \\ *Corresponding author: kokchiang.ng@leonghing.com
}

\begin{abstract}
The synthesis of $C N T s /(S n+M n) O_{x}$ nanocomposites were first attempted through combining the hydro-oxidation of $\mathrm{SnCl}_{2}$ to $\mathrm{SnO}_{2}$ and the reduction of $\mathrm{KMnO}_{4}$ to $\mathrm{MnO}_{2}$ onto CNTs in this work. The reducing presence of $\mathrm{SnCl} \mathrm{C}_{2}$ accelerated the deposition of $\mathrm{MnO}_{2}$ from 7 days to a day. Subsequently, CNTs/(Sn+Mn)O $\mathrm{O}_{x}$ nanocomposites were characterised by X-ray diffraction, scanning and transmission electron microscopy, cyclic voltammetry, and galvanostatic charge-discharge. These microstructure and electrochemical results indicated that this nanocomposite showed synergetic effect in term of specific capacitance, charge storage capacities and exceptional cycling stability. All these enhanced electrochemical properties were attributed to increased surface area, increased utilisation of co-deposited cassiterite-type $\mathrm{SnO}_{2}$ nanoparticulates and birnessite $\mathrm{MnO}_{2}$ monolayer. Additionally, their improved electronic conductivity facilitated better mass transport of ions during charging and discharging process. Based on the findings above, $C N T s /(S n+M n) O_{x}$ nanocomposite will be served as promising and affordable positive electrode materials for high performance supercapacitors.
\end{abstract}

Keywords: Energy Storage, Cassiterite, Manganese Oxide, Nanocomposites, Supercapacitors

\subsection{INTRODUCTION}

The depletion of fossil fuel has urged the development of more sustainable energy sources. Extensive efforts have been put for developing more sustainable energy storage devices such as supercapacitors. Supercapacitors fill in the gap between conventional capacitors and batteries by showing best power characteristics. They provide higher power densities, higher energy densities and longer cycle life [1]. The superior electrochemical performance of supercapacitors is mainly attributed to the electrode materials used. Three main materials for fabricating supercapacitors are metal oxide [2], electronically conducting polymer [3] and carbon-based supercapacitors [4].
In the case of carbon-based supercapacitors, carbonnanotubes (CNTs) have been heavily used as electrode materials. The interconnected nanoporous structure of CNTs specifically opened mesopores allows better mass transport of ions during charging and discharging than activated carbon. Moreover, CNTs are much better than activated carbon in term of conductivity, corrosion resistance, mechanical strength, temperature stability and ease of functionalization. Due to those forementioned properties of CNTs, the development of carbon nanotubebased (CNTs) supercapacitors was first adopted in American aerospace and military application. These sectors heavily rely on the use of supercapacitors as energy storage devices in their light weight hybrid system such as electric satellite, pulse power and propulsion systems [5]. 
Recently, on-going researches on CNT-based supercapacitor have emphasized on the deposition of transition metal oxides which have higher specific capacitance onto CNTs to enhance the pseudocapacitance performance of CNTs. This is due to the fact that transition metal oxides exhibit fairly higher electronic conductivity than CNTs. Transition metal oxides such as $\mathrm{MnO}_{2}, \mathrm{NiO}$, $\mathrm{SnO}_{2}, \mathrm{Co}_{2} \mathrm{O}_{3}$ have been introduced onto CNTs through different deposition methods and studied in term of their electrochemical performance. For instance, two separate nanocomposites namely $\mathrm{CNTs} / \mathrm{MnO}_{2}$ and CNTs/ $\mathrm{SnO}_{2}$ were synthesized and reported to show improved pseudo-capacitance in the work by $\mathrm{Ng}$ and co-workers [6]. They successfully demonstrated the deposition of $\mathrm{MnO}_{2}$ and $\mathrm{SnO}_{2}$ onto CNTs through simple redox and hydro-oxidation reactions separately. Both $\mathrm{CNTs} / \mathrm{MnO}_{2}$ and $\mathrm{CNTs} / \mathrm{SnO}_{2}$ nanocomposites served as positive and negative electrode respectively and showed superior charge-storage capacity, high cell voltage, cycle life, and electrochemical kinetics. The improved capacitance was observed as these nanomaterials combined both ion adsorption and fast redox reactions.

$\mathrm{SnO}_{2}$ has recently been reported to exhibit pseudocapacitance behaviour with long cycle life in aqueous solutions. This material has traditionally been investigated for lithium ion battery applications but gained light in the recent years with the growing demand for greater power in applications utilising supercapacitors. Wu et al. [7] has shown that specific capacitances of $298 \mathrm{~F} / \mathrm{g}$ and 125 F/g can be achieved at scan rates of 10 and $200 \mathrm{mV} / \mathrm{s}$ respectively on $\mathrm{SnO}_{2}$ prepared by cathodic deposition at a constant current of $2.5 \mathrm{~mA} / \mathrm{cm}^{2}$. Rajendra Prasad and Miura [8] on the other hand also reported a maximum specific capacitance of $285 \mathrm{~F} / \mathrm{g}$ at a scan rate of $10 \mathrm{mV} / \mathrm{s}$ with $\mathrm{SnO}_{2}$ prepared via potentiodynamic deposition at a scan rate of $200 \mathrm{mV} / \mathrm{s}$. $\mathrm{SnO}_{2}$ has also been reported to be inserted in various different transition metal oxides or conducting polymers [9] as mixed composites for supercapacitor applications due to its pseudo-capacitive and other encouraging properties as will be discussed below. In particular, $\mathrm{SnO}_{2}$ has been extensively studied in some complicated oxides with $\mathrm{RuO}_{2}$. Such composites have resulted in the reduction of the overall cost of the synthesis due to the known high cost of the $\mathrm{RuO}_{2}$ oxides. $\mathrm{RuO}_{2}$ has very high specific capacitance but is low in conductivity $[10,11]$. Because of this very reason its usages are only limited to thin film applications in consumer products such as mobile phone and portable electronics. This drawback of $\mathrm{RuO}_{2}$ may be overcome by introducing a more conducting oxide such as $\mathrm{SnO}_{2}$ which is traditionally used in many semiconductor and electronic devices as transparent conducting materials [12]. $\mathrm{SnO}_{2}$ is also known to have lower toxicity as compared to some other transition metal compounds used in supercapacitors $[12,13]$. The various synthesis methods for the Ru-Sn composites include the DC reactive sputtering carried out by Kim et al. [14], hydrothermal synthesis by Wang and $\mathrm{Hu}$ [15], co-annealing by Hu et al. [16] and sol gel process by $\mathrm{Wu}$ et al. [16]. $\mathrm{SnO}_{2}$ has also been combined with other metal oxides such as $\mathrm{Al}_{2} \mathrm{O}_{3}$ [17], $\mathrm{V}_{2} \mathrm{O}_{5}$ [18], and $\mathrm{In}_{2} \mathrm{O}_{3}$ [19].

Manganese dioxide, $\mathrm{MnO}_{2}$, on the other hand has always been utilised in many electrochemical power sources dating back to the work of Leclanché in the 1980s in his work with alkaline batteries [20]. In the recent years, $\mathrm{MnO}_{2}$ has been extensively reported in a wide range of journals as a promising electrode material for the electrochemical capacitors. This is due to its low cost and the environmental consideration when compared to other oxides besides the fairly high pseudo-capacitance exhibited. The investigation on this oxide started with only 6 papers from the year 1999-2000 to more than 75 papers from 2004-2007. There have been attempts to further improve the performance of $\mathrm{MnO}_{2}$ by seeking synergetic effect of combining the oxide with other transition metal oxides or conducting polymers [21]. Among the transition metal oxides and conducting polymers combined with $\mathrm{MnO}_{2}$ for the improvement of the specific capacitance include $\mathrm{NiO}$ [22], $\mathrm{Co}_{2} \mathrm{O}_{3}$ [22], $\mathrm{PbO}_{2}$ [26], $\mathrm{Fe}_{2} \mathrm{O}_{3}$ [27, 28], $\mathrm{MoO}_{2}$ [29], $\mathrm{V}_{2} \mathrm{O}_{5}$ [30], PANI [31], and PPy [32]. The Ni-Mn hydroxide reported by Shlyakhtin et al. showed significant reversible electrochemical capacity at high discharge rate (up to $70 \mathrm{mAh} / \mathrm{g}$ at $\mathrm{I}=70 \mathrm{~mA} / \mathrm{cm}^{2}$ ) [33, 34]. Prasad and Miura [26] and Zhao et al. [23-25] also reported improvement with the addition of $\mathrm{Co}_{2} \mathrm{O}_{3}$ in the specific capacitance of $\mathrm{MnO}_{2}$. Remarkably high specific capacitance was achieved with the electrochemically synthesised $\mathrm{MnO}_{2}$ embedded in PPy besides improving its charge-discharge stability by Sharma et al. [32].

However, to date, there have not been any studies to combine the $\mathrm{MnO}_{2}$ with $\mathrm{SnO}_{2}$, despite the high specific capacitance achievable by both oxides [6]. $\mathrm{SnO}_{2}$ has properties which are complementary to those of $\mathrm{MnO}_{2}$. The tendency to form nanoparticulate, even in the hydrous form, can increase the specific area available for pseudocapacitive reactions. The high conductivity, i.e. 102 to 103 $\mathrm{S} / \mathrm{cm}[35,36]$ of $\mathrm{SnO}_{2}$ is also higher than that of $\mathrm{MnO}_{2}(10-$ 3 to $10-4 \mathrm{~S} / \mathrm{cm}$ ) [37, 38-40], which would in turn improve the electrochemical utilisation of $\mathrm{MnO}_{2}$ when combined with the $\mathrm{SnO}_{2}$. In this work, the co-deposition of $\mathrm{MnO}_{2}$ and $\mathrm{SnO}_{2}$ was attempted and the deposition of $\mathrm{MnO}_{4}$ was accelerated due to the reducing presence of $\mathrm{SnCl}_{2}$. The synergetic effects of the combined metal oxides in term 
of electrochemical performance will be further discussed. The nanocomposite synthesised is denoted as CNTs/ $(\mathrm{Sn}+\mathrm{Mn}) \mathrm{Ox}$.

\subsection{METHODOLOGY}

Synthesis of the CNTS/(Sn+Mn)O $O_{x}$ nanocomposites $-1.0 \mathrm{~g}$ of $\mathrm{SnCl}_{2}$ salt (Sigma-Aldrich, 98\%) was dissolved in 50.0 $\mathrm{mL}$ of deionised $\mathrm{H}_{2} \mathrm{O}$ with $1.0 \mathrm{~mL}$ of $\mathrm{HCl}(30 \%$ w.t.) and continuously stirred for 1 hour before the addition of acid treated multi-walled CNTs (L. MWNTs-1030, >95\%, 10$30 \mathrm{~nm}$ in diameter, 5-15 $\mu \mathrm{m}$ in length, amorphous carbon < $3 \%$ ). 10mg of acid-treated CNTs were immersed in $\mathrm{SnCl}_{2}$ solution to synthesise nanocomposites with the mixedoxide loadings of $60 \%$ w.t. Subsequently, $1.21 \mathrm{~g}$ of $\mathrm{KMnO}_{4}$ was added to obtain a $\mathrm{Sn}: \mathrm{Mn}$ ratio of 1:1 in the deposited oxides. The mixtures were stirred at $200 \mathrm{rpm}$ for 24 hours. After 24-hr stirring, brown precipitate was settled at the bottom of the flask. The products were filtered and washed with deionised $\mathrm{H}_{2} \mathrm{O}$ prior to 24 -hour drying at $60^{\circ} \mathrm{C}$. The dried products were ground using an agate and pestle.

Chemical and structural characterisation of $C N T s /(S n+M n) O_{x}$ nanocomposites - The ground nanocomposites were characterised by an Environmental Scanning Electron Microscope (SEM, Philips FEI XL30 FEG-ESEM), a low resolution TEM (LR-TEM, JEOL 2000FX) and X-ray diffraction (XRD, Hiltonbrooks DG3 generator plus Philips PW1050/25 goniometer, $\mathrm{CuK \alpha}$ radiation). A Micromeritics ASAP 2020 V3.01 H BET surface area analyser was used to evaluate the surface area of the nanocomposites powders. All samples were dried thoroughly in the conventional oven before the degassing and further heating at $100{ }^{\circ} \mathrm{C}$ for 60 minutes in the machine. Nitrogen sorption isotherms and textural properties of the materials were determined at $77 \mathrm{~K}$ using liquid nitrogen in a conventional volumetric method. The surface areas of the nanocomposites were calculated using the BrunauerEmmett-Teller (BET) technique based on adsorption data in the partial pressure $\left(\mathrm{P} / \mathrm{P}_{0}\right)$ range of 0.05-0.35.

Preparation of nanocomposite thin-films on electrode for electrochemical studies - 95\% w.t. CNTs/ $(\mathrm{Sn}+\mathrm{Mn}) \mathrm{O}_{\mathrm{x}}$ nanocomposite of different oxide loading and 5\% w.t. PTFE binder (60\% w.t. aqueous emulsion of polytetrafluroethylene, Aldrich) were thoroughly dispersed in $4 \mathrm{ml}$ of deionised water. $10.0 \mu \mathrm{l}$ of the mixture was cast onto epoxy-sheathed graphite electrode $(0.25 \mathrm{~cm}$ in diameter) to form a very thin nanocomposite film using electronic micropipette (EDP3 Rainin LTS 10-100 $\mu \mathrm{L}$ with wide orifice tips). Thin nanocomposite films $(65 \mu \mathrm{m}$ on average thickness) on graphite electrodes were dried in desiccators overnight before electrochemical studies
(AUTOLAB PGSTAT30) in a one-compartment threeelectrode cell with the $\mathrm{Ag} / \mathrm{AgCl}(2 \mathrm{M} \mathrm{KCl})$ reference electrode and a graphite counter electrode at room temperature.

\subsection{RESULTS AND DISCUSSIONS}

Figure 1 shows the BET surface area of the nanocomposites of different $(\mathrm{Sn}+\mathrm{Mn}) \mathrm{O}_{x}$ loadings. As stated before, the surface area of the acid-treated CNTs was found to be $107.75 \mathrm{~m}^{2} / \mathrm{g}$. In Figure 1, the BET surface area of the nanocomposites shows an increasing trend up to a mixedoxides loading of $60 \%$ w.t. but a decreasing trend thereafter. The initial increase in surface area can be attributed to the fact that the mixed-oxides by themselves may have a higher surface area as compared to the CNTs. However, the surface area of the mixed-oxides by themselves only would be expected to be slightly less than the surface area recorded for the $\mathrm{CNTs} /(\mathrm{Sn}+\mathrm{Mn}) \mathrm{O}_{\mathrm{x}} 80 \%$ as can be seen from the declining rate of decrease in surface area of the nanocomposites as the loading of the mixed-oxides increases beyond the $60 \%$ w.t. loading. This would also elucidate the reason behind the maximum surface area achieved at $60 \%$ w.t. loading. This is because if the surface area of the mixed-oxides on their own is slightly less than the nanocomposite with $80 \%$ w.t. oxides loading but higher than that of the acid-treated CNTs, the maximum achieved at the loading of $60 \%$ w.t. would be associated with the CNTs providing a three-dimensional nanostructure for the deposition of the mixed-oxides. The $(\mathrm{Sn}+\mathrm{Mn}) \mathrm{O}_{\mathrm{x}}$ on their own may not be able to achieve as high BET surface area without the acid-treated CNTs because they may exist as agglomerates with low porosity. Thus, the CNTs substrate has actually provided a synergetic effect with its structure in improving the overall surface area of the nanocomposite. With the mixed-oxides depositing onto the CNT substrate instead of forming agglomerates together with the nature of the random packing of the CNTs, the nanocomposites formed would have higher porosity than that of the pure mixed-oxides.

In addition, the corrosion phenomenon by $\mathrm{KMnO}_{4}$ on the CNTs at high loading of $\mathrm{MnO}_{2}$ which was previously reported [29] shortened and destroyed the structure of the CNTs substrate in the CNTs/ $\mathrm{MnO}_{2}$ nanocomposite. The decrease in surface area as the mixed-oxides loadings are increased beyond $60 \%$ w.t. may also be associated with the destruction of porous structure provided by the CNTs substrate due to the corrosion by $\mathrm{KMnO}_{4}$. When this happens, the synergetic effect provided by the long entangled framework of the CNTs would be lost, hence the decrease in the BET surface area. 


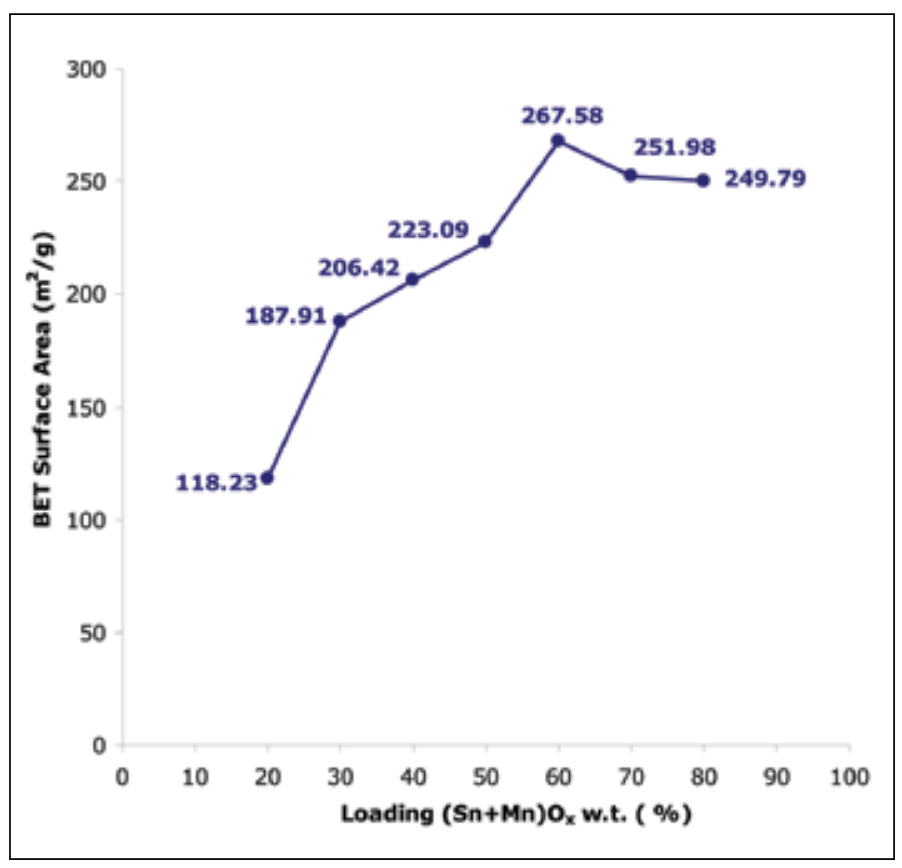

Figure 1: BET surface area of the CNTs/(Sn+Mn) $O_{x}$ nanocomposites at different loadings of $(\mathrm{Sn}+\mathrm{Mn}) \mathrm{O}_{x}$ (i.e. from $20 \%$ to $60 \%$ w.t. $(\mathrm{Sn}+\mathrm{Mn}) \mathrm{O}_{x}$ in $10 \%$ increments)

As the co-deposition of the mixed-oxides is uneven on the surface of the CNTs, the mixed-oxides would in effect introduce more overall surface area to the nanocomposite as compared to oxides which uniformly coat the CNTs. Uniform coating of oxides on the surface CNTs without jagged texture as in our case of the $\mathrm{CNTs} /(\mathrm{Sn}+\mathrm{Mn})$ $\mathrm{O}_{\mathrm{x}}$ would increase the diameter of the nanocomposite fibrils uniformly, thus, would be expected to show lower surface area as compared to the acid-treated CNTs. The nanocrystalline particulates of $4 \mathrm{~nm}$ in diameter of the $\mathrm{SnO}_{2}$ which are enveloped by the amorphous $\mathrm{MnO}_{2}$ as seen in the HR-TEM images have certainly contributed to the increase in surface area of the nanocomposites. This is because the nanoparticulates themselves have very high surface area due to the size and it is also because of these nano-agglomerates which promotes the jagged morphology of the nanocomposites as viewed under the SEM machine.

Figures 2 (a) and (b) show the SEM images of the $\mathrm{CNTs} /(\mathrm{Sn}+\mathrm{Mn}) \mathrm{Ox} 60 \%$ w.t. nanocomposites at different magnifications. Jagged and consistent coarse surfaces of CNTs clearly shown in Figures $2(a-b)$ were caused by the deposition of $(\mathrm{Sn}+\mathrm{Mn}) \mathrm{Ox}$ agglomerates at nanoscale. The co-deposited oxides on CNTs at the metal oxide loading of $60 \%$ w.t caused an overall increase in the fibril diameter of nanocomposite. The co-deposition of metal oxides, however, did not cause opening blocking to the randomly packed CNTs bundles. These SEM images indicated that co-deposition of metal oxide was formed on the surface of CNT substrate. Thus, the porous three-dimensional structure of CNTs was still retained. Such porous structure was necessary for the ease of intercalations and deintercalations of cations from the electrolyte during the charge and discharge cycles. This would allow a better kinetic reversibility and improve the capacitance of the nanocomposite.
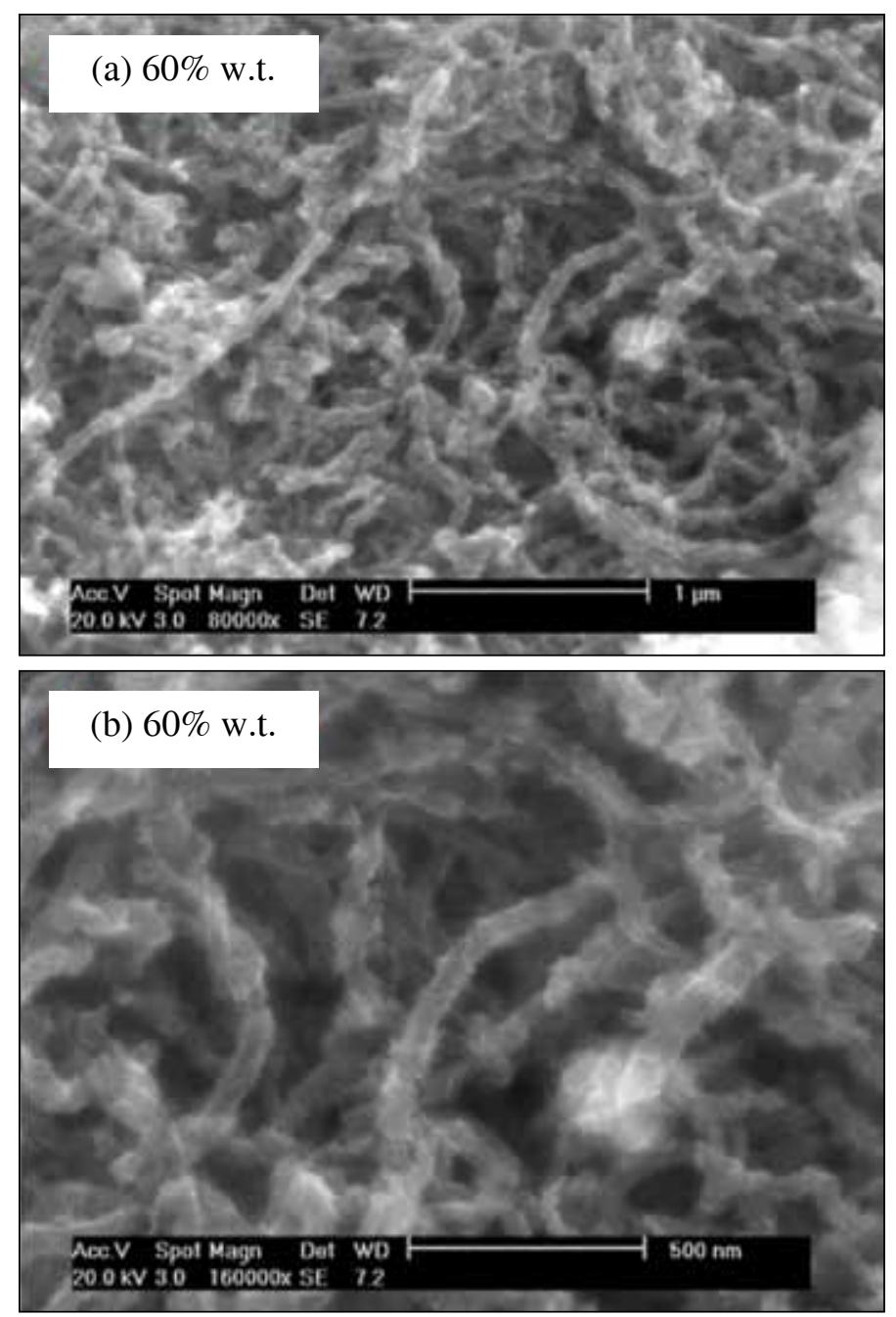

Figures 2 (a) and (b). SEM images of the CNTs/ $(\mathrm{Sn}+\mathrm{Mn}) \mathrm{O}_{x}$ $60 \%$ w.t. nanocomposites at magnifications of 80,000 and 160,000 times

Figures 3 (a) to (e) show TEM images of the CNTs/ $(\mathrm{Sn}+\mathrm{Mn}) \mathrm{O}_{\mathrm{x}} 60 \%$ w.t. nanocomposite, while Figures 3 (f) and (g) depict the darkfield images of the fibrils of the nanocomposites. Broken CNT fibrils heavily coated with $(\mathrm{Sn}+\mathrm{Mn}) \mathrm{O}_{\mathrm{x}}$ were observed in Figures $3(\mathrm{a}-\mathrm{b})$. The structural destruction of CNTs was caused by the reduction reaction of $\mathrm{KMnO}_{4}$ to $\mathrm{MnO}_{2}$ in which the carbon in CNTs was consumed. The deposition mechanism of $\mathrm{MnO}_{2}$ on CNTs is shown as below [6]. The consumption of carbon in the reduction reaction resulted in the formation of shorter fibrils. 


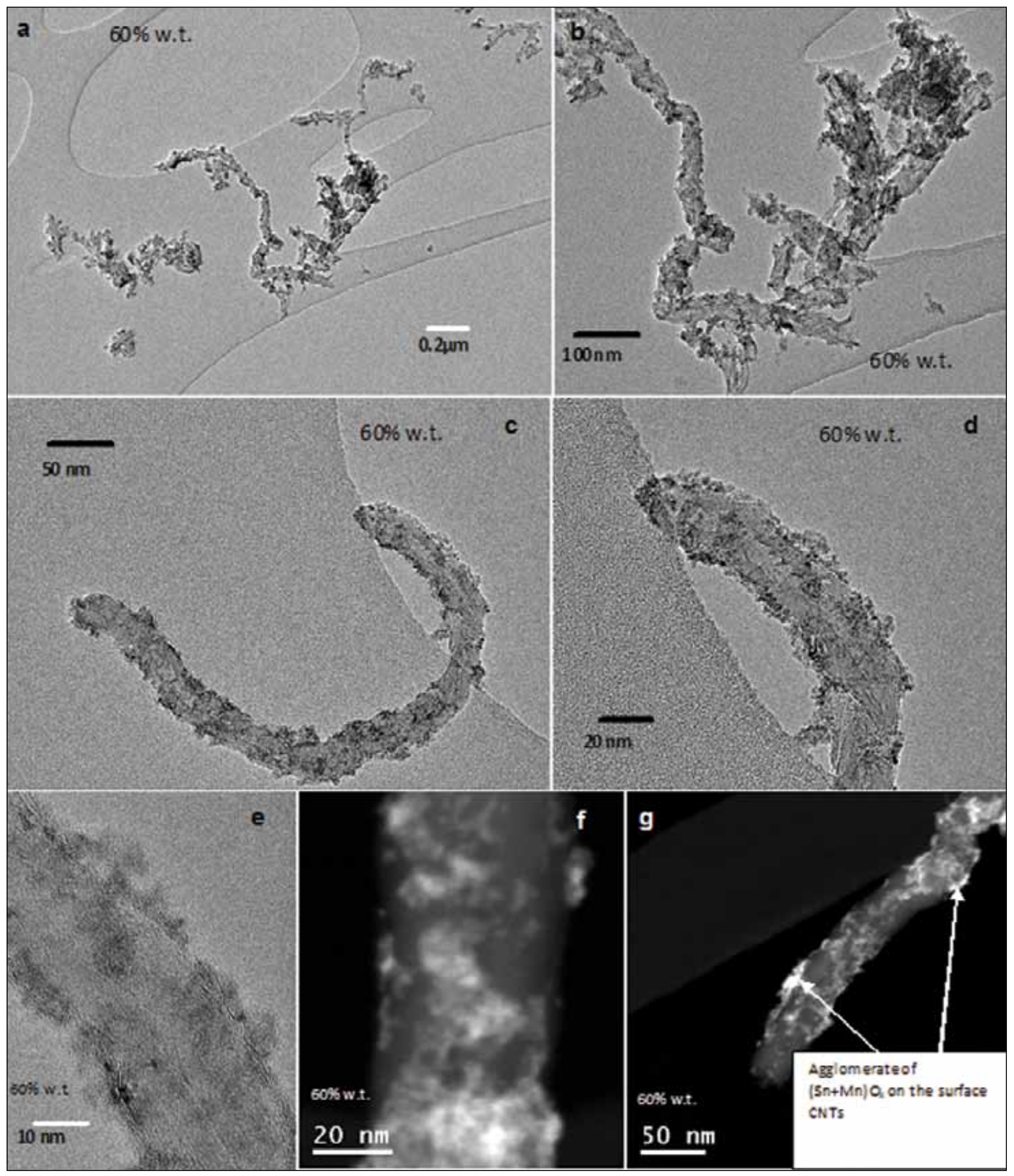

Figure 3: TEM images of the CNTs/(Sn+Mn) $O_{x} 60 \%$ w.t. nanocomposite at different magnifications

$4 \mathrm{KMnO}_{4}(\mathrm{aq})+3 \mathrm{C}(\mathrm{s})+\mathrm{H}_{2} \mathrm{O} \rightarrow 4 \mathrm{MnO}_{2}(\mathrm{~s})+$ $\mathrm{K}_{2} \mathrm{CO}_{3}(\mathrm{aq})+2 \mathrm{KHCO}_{3}(\mathrm{aq})$

The distribution of the metal oxide across the surface of CNTs was confirmed by the darkfield images in Figures
(1) 3 (f) and (g). The bright spots on the darker fibrils were the deposited metal oxides through redox reaction. Agglomerates with thickness of 5-10 nm were observed in Figure 3 (e). This was believed that those agglomerates were mixture of nanoparticulates of $\mathrm{SnO}_{2}$ and $\mathrm{MnO}_{2}$ 
from the results of the XRD. This uneven deposition of nano agglomerates was also initiated by the adsorption of tin ions onto the surface of acid-treated CNTs due to electrostatic attraction, subsequent in situ oxidisation to $\mathrm{SnO}_{2}$ nanoparticulates by $\mathrm{O}_{2}$ dissolved in the solution. The exact deposition mechanism of $\mathrm{SnO}_{2}$ is shown below:

$2 \mathrm{SnCl}_{2}(\mathrm{aq})+2 \mathrm{H}_{2} \mathrm{O}+\mathrm{O}_{2} \rightarrow 2 \mathrm{SnO}_{2}(\mathrm{~s})+$

$4 \mathrm{HCl}(\mathrm{aq})$

This controlled deposition of $\mathrm{SnO}_{2}$ on the CNTs resulted in a thinly and dispersedly coated $\mathrm{SnO}_{2}$ based nanocomposite. Further deposition of the $\mathrm{SnO}_{2}$ on the CNTs greatly depends on the adsorption of tin ions on the as-originated $\mathrm{SnO}_{2}$ coating, which is a slow crystalisation route. Following such deposition mechanism, uneven distribution of $\mathrm{SnO}_{2}$ nano aggloramates was observed and contributed to the jagged surface of CNTs observed in Figures 3 (a-b). Additionally, rapid co-deposition of $\mathrm{MnO}_{2}$ and $\mathrm{SnO}_{2}$ prevented the formation of thick coatings of $\mathrm{MnO}_{2}$, as well as embedding $\mathrm{SnO}_{2}$ nanocrystals in the structure. The thin coating of both metal oxides led to reduced electron transport lengths and ion diffusion distances. The improvement of electron kinetic was thus expected.

From the reactions (1) and (2), it can be seen that the formation of the $\mathrm{MnO}_{2}$ solid involved the reduction of $\mathrm{MnO}_{4}^{-}$ions, while in the controlled hydro-oxidation reaction, $\mathrm{SnO} 2$ nanoparticulates were formed via the oxidation of the $\mathrm{Sn}^{2+}$ ions on CNTs. Instead of just CNTs acting as the reducing agent for the deposition of $\mathrm{MnO}_{2}$, the acceleration of such deposition to a day was also due to the reducing presence of $\mathrm{SnCl}_{2}$ solution which was acidic in nature. This work demonstrated that the reduction of $\mathrm{KMnO}_{4}$ was much preferably under acidic condition. On the other hand, the formation of $\mathrm{SnO}_{2}$ on CNTs did not require the active participation of the carbon according to the hydro-oxidation reaction above, it was found that CNTs were still instrumental in the codeposition, as they provided nucleation sites for the deposition of $\mathrm{SnO}_{2}$ nanoparticulates.

To further verify the types of metal oxide in those nano agglomerates, one of agglomerates shown in Figure 3-1 (c) was enlarged for determining the interplanar spacing of fringes exhibited by the dark crystalline grains and outer coating of the dark crystalline grains in Figure 3-1 (d). The measured d-spacing for the fringes found in the crystalline grains and the outer coating of the crystalline grains were approximately $0.3 \mathrm{~nm}$ and $0.7 \mathrm{~nm}$ respectively. The value of $0.3 \mathrm{~nm}$ corresponds to the $\mathrm{d}(110)$ of the cassiterite- $\mathrm{SnO}_{2}$ in the JCPDS data of 41-1445, while $0.7 \mathrm{~nm}$ corresponds to the $\mathrm{d}(001)$ of the monoclinic- $\mathrm{MnO}_{2}$ in the JCPDS data of 65-1798. These TEM images evidently demonstrate that CNTs were not the only nucleation sites for $\mathrm{MnO}_{2}$, $\mathrm{SnO}_{2}$ nanoparticulate clusters simultaneously served as heterogeneous sites for the nucleation and growth of $\mathrm{MnO}_{2}$ nanomaterials. This substantiates the claim that
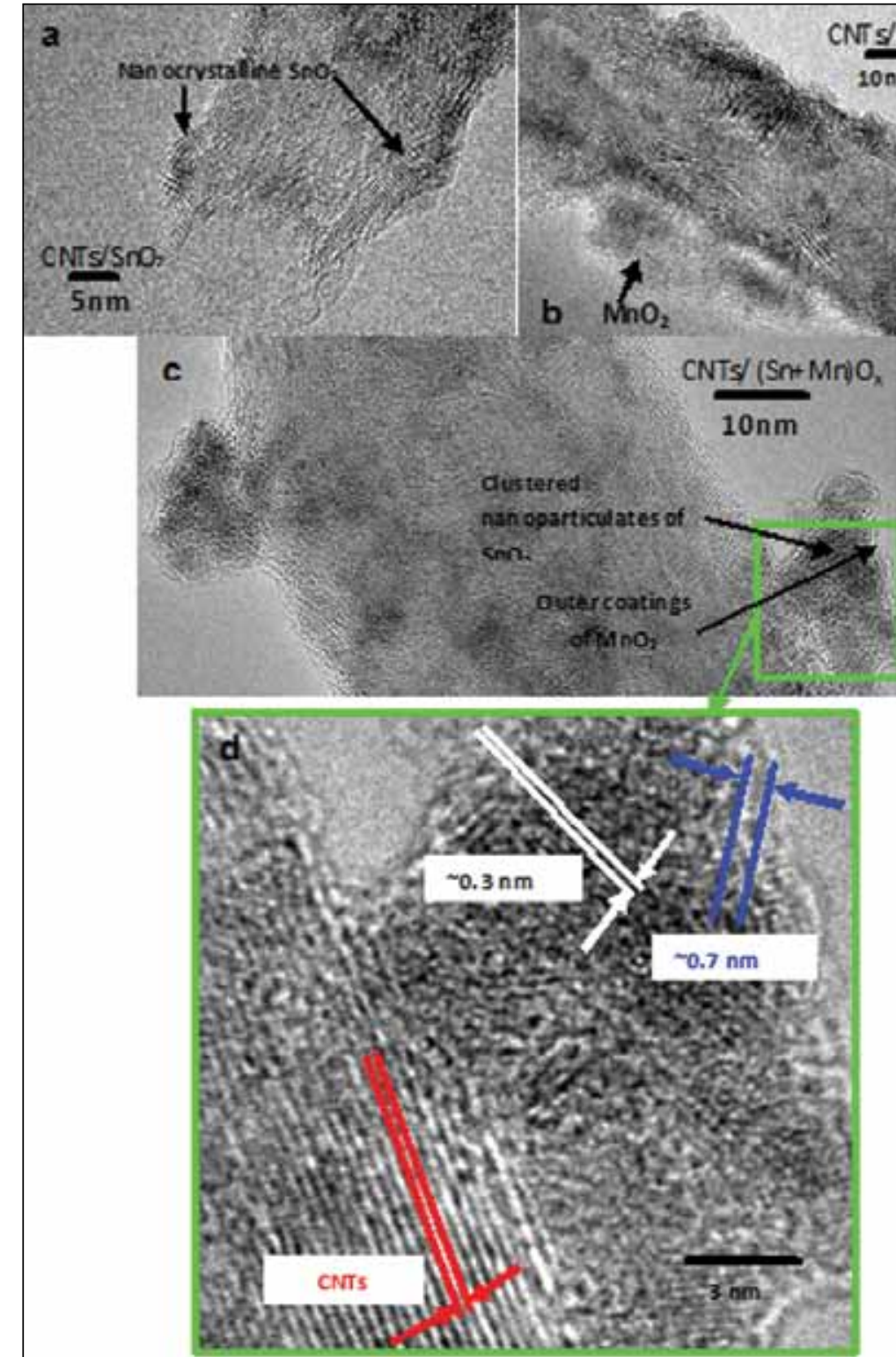

Figure 3-1 (a) CNTs/SnO ${ }_{2} 60 \%$ w.t. nanocomposite (b) CNTs $/ \mathrm{MnO}_{2} 60 \%$ w.t. nanocomposite, (c) the nano-agglomerates on the $C N T s /(S n+M n) O_{x} 60 \%$ w.t. nanocomposite surface, and (d) the d-spacing values of the fringes observed from the enlarged portion of image (c) 
$\mathrm{MnO}_{2}$ layers were blanketing the agglomerates of the $\mathrm{SnO}_{2}$ nanoparticulates which together formed the lumps observed.

Figure 4 shows the XRD patterns of the acid-treated CNTs, nanocomposites of $\mathrm{CNTs} / \mathrm{SnO}_{2} 60 \%$ w.t. [6], nanocomposites of $\mathrm{CNTs} / \mathrm{MnO}_{2} 60 \%$ w.t. [6], and nanocomposites of $\mathrm{CNTs} /(\mathrm{Sn}+\mathrm{Mn}) \mathrm{O}_{\mathrm{x}}$ of $60 \%$. The metal oxides deposited on CNTs caused the broadening of the CNT peaks and made those peaks become less distinctive. The $\mathrm{SnO}_{2}$ presence corresponds to the cassiterite-type $\mathrm{SnO}_{2}$, while the $\mathrm{MnO}_{2}$ to the birnessite-type $\mathrm{MnO}_{2}$ and both match the JCPDS data of 41-1445 and 42-1317 respectively. The cassiterite-type $\mathrm{SnO}_{2}$ deposited had a structure which corresponds to $\mathrm{a}=4.738, \mathrm{~b}=4.738$, and $\mathrm{c}$ $=3.187 \AA$, while the birnessite-type $\mathrm{MnO}_{2}$ was monoclinic with $\mathrm{a}=5.150, \mathrm{~b}=2.844, \mathrm{c}=7.159 \AA$, and $\beta=100.64^{\circ}$ in accordance with the XRD data obtained.

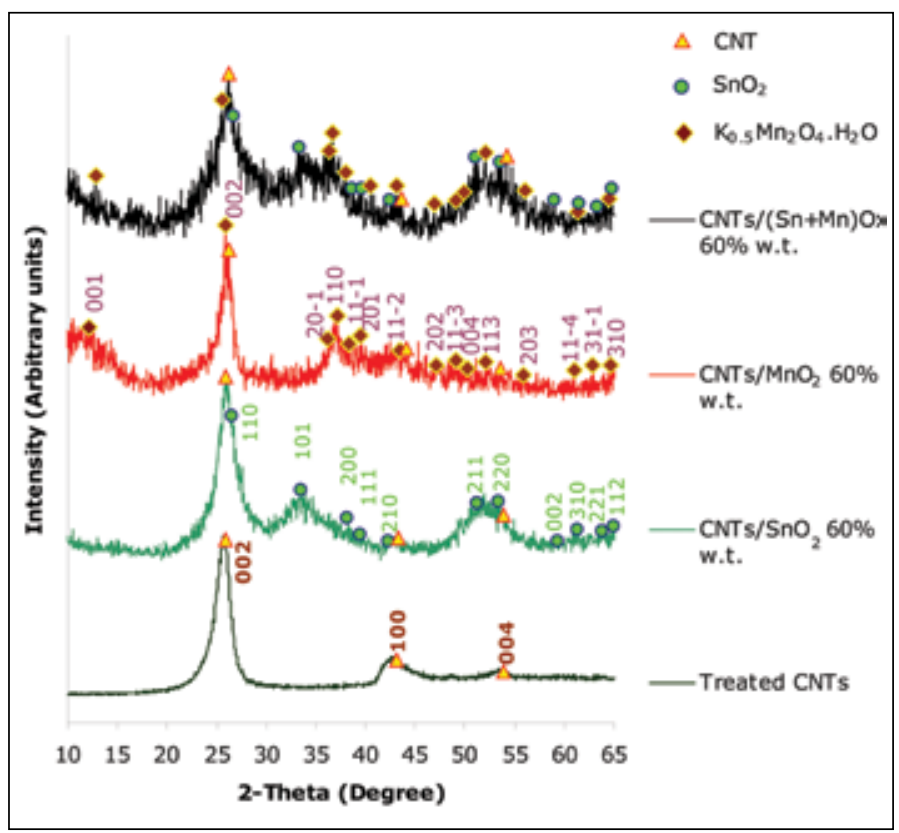

Figure 4: X-ray diffraction patterns of the acid-treated CNTs, $\mathrm{CNTs} / \mathrm{SnO}_{2} 60 \%$ w.t., CNTs $/ \mathrm{MnO}_{2} 60 \%$ w.t., and CNTs/ $(\mathrm{Sn}+\mathrm{Mn}) \mathrm{O}_{x} 60 \%$ w.t. nanocomposites

Figure 5 depicts the cyclic voltammogram of the $\mathrm{CNTs} /(\mathrm{Sn}+\mathrm{Mn}) \mathrm{O}_{\mathrm{x}} 60 \%$ w.t. nanocomposite in a $2.0 \mathrm{M} \mathrm{KCl}$ which is relatively rectangular in shape similar to that of the pure double-layer storage by carbon. The rectangular shaped voltammogram is due to the continuous electron transfer into the wide range of energy states closely located near the redox active sites on the surface of the electrode in semiconductors such as $\mathrm{SnO}_{2}$ and $\mathrm{MnO}_{2}$. In the anodic sweep, oxidation from $\mathrm{Mn}$ (III) to $\mathrm{Mn}$ (IV) took place together with the protons and cations intercalations and adsorptions (for both $\mathrm{SnO}_{2}$ and $\mathrm{MnO}_{2}$ ), while in the cathodic scan, the reduction of Mn(IV) to Mn(III) occurred, coupled with the proton and cations deintercalations and desorptions. Based on the findings of charge storage mechanism of $\mathrm{MnO}_{2}$ by Lee and Goodenough et al. [43] and electrochemical performance of $\mathrm{SnO}_{2}$ by $\mathrm{Wu}$ et al. [44], the charge storage mechanism of the CNTs/( $\mathrm{Sn}+\mathrm{Mn}) \mathrm{O}_{\mathrm{x}}$ nanocomposite involving surface adsorption of the alkali metal cation $\left(\mathrm{K}^{+}\right)$on the $\mathrm{SnO}_{2}$ and $\mathrm{MnO}_{2}$ in this work can be expressed as the following equations.

$\left(\mathrm{SnO}_{2}\right)_{\text {surface }}+a \mathrm{~K}^{+}+a \mathrm{e}^{-} \rightleftharpoons\left(\mathrm{SnO}_{2}^{-} \mathrm{K}^{+}\right)_{\text {surface }}$
$\left(\mathrm{MnO}_{2}\right)_{\text {surface }}+x \mathrm{~K}++x \mathrm{e}^{-} \rightleftharpoons\left(\mathrm{MnO}_{2}^{-} \mathrm{K} x^{+}\right)_{\text {surface }}$

In the amorphous $\mathrm{SnO}_{2}$ and $\mathrm{MnO}_{2}$, there exist facile diffusion of protons into the hydrous structure of both oxides, the cation $\left(\mathrm{K}^{+}\right)$would be able to intercalate and deintercalate into the hydrous layer and lattice of the thin deposition of the oxides on the CNTs during the redox reaction corresponding to the following equations;

$\mathrm{SnO}_{2}+a \mathrm{~K}^{+}+a \mathrm{e}^{-} \rightleftharpoons \mathrm{SnOOK}_{a}$
$\mathrm{MnO}_{2}+x \mathrm{~K}^{+}+x \mathrm{e}^{-} \rightleftharpoons \mathrm{MnOOK}_{x}$

The second pseudo-capacitive mechanism includes the intercalation of protons $\left(\mathrm{H}^{+}\right)$in the bulk of the nanocomposite during reduction and deintercalations in the oxidation cycle. Wu et al. [44] and Pang et al. [45] proposed the following reactions for the $\mathrm{SnO}_{2}$ and $\mathrm{MnO}_{2}$ respectively;

$\mathrm{SnO}_{2}+b \mathrm{H}^{+}+b \mathrm{e}^{-} \rightleftharpoons \mathrm{SnOOH}_{b}$

$\mathrm{MnO}_{2}+y \mathrm{H}^{+}+y \mathrm{e}^{-} \rightleftharpoons \mathrm{MnOOH}_{y}$

The simultaneous occurrence of the intercalation/ deintercalation of the protons and alkali metal cations have been confirmed in the recent studies by Toupin et al. [46] using the X-ray photoelectron spectroscopy (XPS) technique. In addition, Toupin et al. [46] had demonstrated that there is a change in the state of $\mathrm{MnO}_{2}$ during the charge and discharge cycle, where there exist components in the XPS results which correspond to the manganese oxidation state of 4 and 3 for the oxidised and reduced film electrodes respectively. Combining the simultaneous reactions would give the following equations for the pseudo-capacitive storage mechanism of the CNTs/ $(\mathrm{Sn}+\mathrm{Mn}) \mathrm{O}_{\mathrm{x}}$ nanocomposite in this study;

Oxidation:

$\mathrm{Sn}(\mathrm{IV})_{(a+b)} \mathrm{OOK}_{a} \mathrm{H}_{b}+\mathrm{Mn}(\mathrm{III})_{(x+y)} \mathrm{Mn}(\mathrm{IV})_{1-(x+y)}$

$(b+y) \mathrm{H}^{+}+(a+b+x+y) \mathrm{e}^{-}$ 
Reduction:

$\mathrm{Sn}(\mathrm{IV}) \mathrm{O}_{2}+\mathrm{Mn}(\mathrm{IV}) \mathrm{O}_{2}+(a+x) \mathrm{K}^{+}+(b+y) \mathrm{H}^{+}+$

$(a+b+x+y) \mathrm{e}^{-} \rightarrow \mathrm{Sn}(\mathrm{IV})_{(a+b)} \mathrm{OOK}_{a} \mathrm{H}_{b}+\mathrm{Mn}(\mathrm{III})_{(x+y)}$

$\mathrm{Mn}(\mathrm{IV})_{1-(x+y)} \mathrm{OOK}_{x} \mathrm{H}_{y}$

Redox:

$\mathrm{SnO}_{2}+\mathrm{MnO}_{2}+(a+x) \mathrm{K}^{+}+(b+y)^{\mathrm{H}+}+$

$(a+b+x+y) \mathrm{e}^{-} \rightleftharpoons \operatorname{SnOOK}_{a} \mathrm{H}_{b}+\mathrm{MnOOK}_{x} \mathrm{H}_{y}$

Figure 5 also shows that the $\mathrm{CNTs} /(\mathrm{Sn}+\mathrm{Mn}) \mathrm{O}_{\mathrm{x}}$ nanocomposite has very good positive polarisation up to a value of $0.9 \mathrm{~V}$ (oxygen evolution occurs at $0.6 \mathrm{~V}$ vs. Ag/ $\mathrm{AgCl}$ in neutral solution [47]). For a neutral $\mathrm{pH}$ value of 6.67 in the aqueous $\mathrm{KCl}$ electrolyte, a potential window of $1 \mathrm{~V}$ can be achieved with no oxygen evolution observed in the potential range selected as can be seen in the cyclic voltammogram where there are no fast current leaps of a gas evolution present [47].

Figure 6 shows the cyclic voltammograms and the corresponding voltage dependent normalised capacitance of the thin casted film of the CNTs/(Sn+Mn)O $60 \%$ w.t. nanocomposite at different sweep rates of 5, 10, 20, 50, 70, and $100 \mathrm{mV} / \mathrm{s}$ at a potential range of -0.1 to $0.9 \mathrm{~V}$ against $\mathrm{Ag} / \mathrm{AgCl}$. The shapes of voltage dependent normalised capacitance curves are similar to that of the cyclic

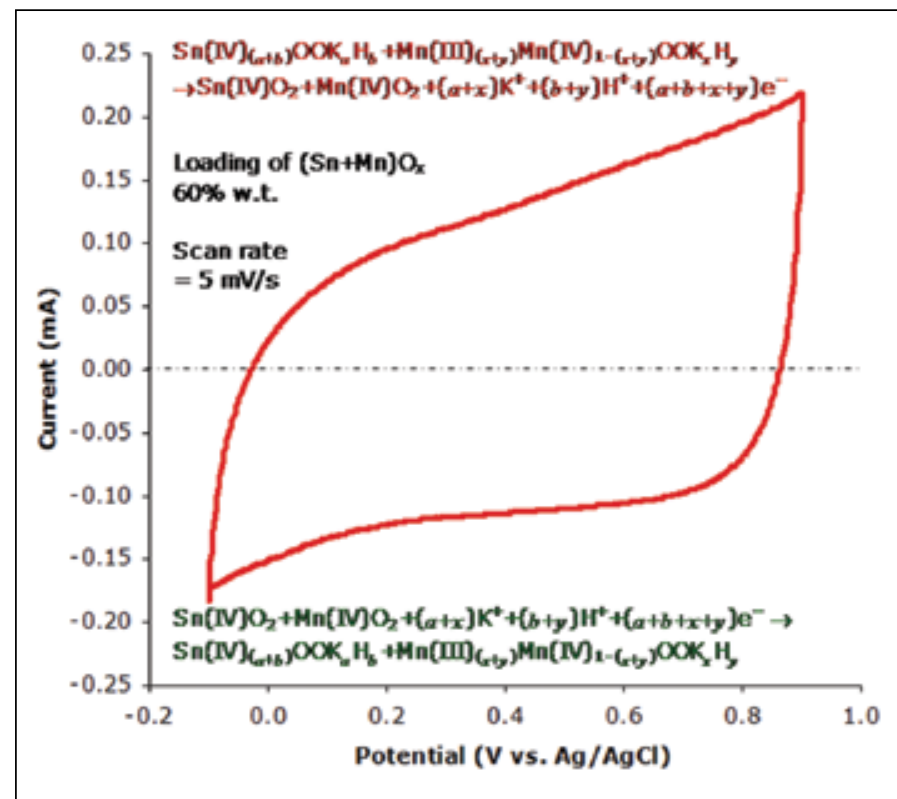

Figure 5: The cyclic voltammogram of the

$\mathrm{CNT} /(\mathrm{Sn}+\mathrm{Mn}) \mathrm{O}_{x} 60 \%$ w.t. nanocomposite at a scan rate of $5 \mathrm{mV} / \mathrm{s}$ in $2.0 \mathrm{M} \mathrm{KCl}$ electrolyte

voltammograms, thus enabling a better examination of the cyclic voltammograms of the lower scan rates such as 5 $\mathrm{mV} / \mathrm{s}$. The cyclic voltammogram of the $\mathrm{CNTs} /(\mathrm{Sn}+\mathrm{Mn}) \mathrm{Ox}$ nanocomposite approximates to an ideal behaviour at the lowest sweep-rate of $5 \mathrm{mV} / \mathrm{s}$, i.e. a voltammogram having an almost rectangular shape and mirror-image symmetry of the current responses about the zero-current line can be

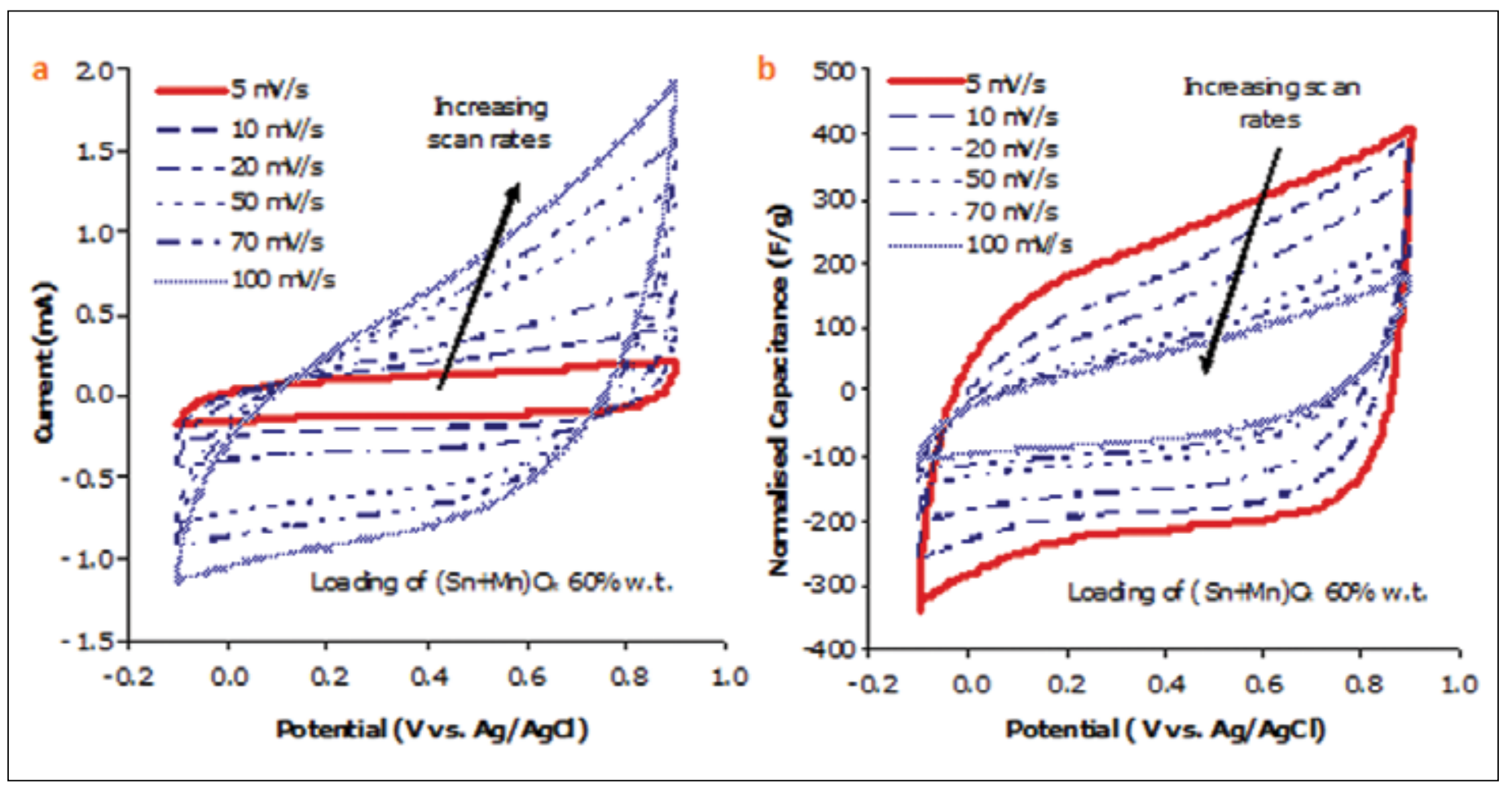

Figure 6: (a) Cyclic voltammograms and (b) mass-normalised capacitance vs. potential (vs. Ag/AgCl) of the CNTs/(Sn+Mn) $\mathrm{O}_{x}$ $60 \%$ w.t. nanocomposite at various scan rates $(5,10,20,50,70$ and $100 \mathrm{mV} / \mathrm{s})$ in $2.0 \mathrm{M} \mathrm{KCl}$. 
observed. With increasing scan rates, the voltammograms become deformed from the rectangular shape. Decreasing the scan rates enables the ions to reach deeper into the electrode whilst interacting with active materials more completely (redox reactions) to give the pseudo-capacitive effect which results in a more rectangular curve such as the one observed at the scan rate of $5 \mathrm{mV} / \mathrm{s}$.

The mass specific capacitance for the $\mathrm{CNTs} /(\mathrm{Sn}+\mathrm{Mn}) \mathrm{O}_{\mathrm{x}} \quad 60 \%$ w.t. nanocomposite, which decreased from $222.74 \mathrm{~F} / \mathrm{g}$ to $71.69 \mathrm{~F} / \mathrm{g}$ as the scan rate increased from 5 to $100 \mathrm{mV} / \mathrm{s}$, indicated that parts of the surface of the nanocomposite in the electrode were inaccessible at high sweep rates [48-50]. These inaccessible parts were likely the inner active sites that could not sustain the redox transitions completely at higher sweep rates as a result of the diffusion effect of protons within the deposited $(\mathrm{Sn}+\mathrm{Mn}) \mathrm{O}_{x}$ [49]. Thus, the specific capacitance obtained at the lowest scan rate was of the highest utilisation of the pseudo-capacitive material in the nanocomposite among all the scan rates examined. Additionally, the specific capacitance at the lowest scan rate of this nanocomposite was much higher than those reported in the CNTs- $\mathrm{MnO}_{2}$ and CNTs-SnO ${ }_{2}$ nanocomposites prepared by $\mathrm{Ng}$ and coworkers [6]. This clearly indicated the synergetic effect of the co-deposition of $\mathrm{SnO}_{2}$ and $\mathrm{MnO}_{2}$ onto CNTs in term of specific capacitance.

Figure 7 shows the galvanostatic charge-discharge properties of the nanocomposites of the CNTs/(Sn+Mn)
Ox $60 \%$ w.t. against $\mathrm{Ag} / \mathrm{AgCl}$ at different normalised currents of $0.4,0.8,1.6,3.2$ and $6.4 \mathrm{~A} / \mathrm{g}$. All the potentialtime plots from the galvanostatic charge-discharge test show good linear variations of the potential (vs. $\mathrm{Ag}$ / $\mathrm{AgCl}$ ) with respect to time in the potential range of -0.1 to $0.9 \mathrm{~V}$ for this nanocomposite. This was an indication of excellent capacitive behaviour by the nanocomposite at all normalised currents applied. Specifically, CNTs/ (Sn+Mn)Ox 60\% w.t. nanocomposite exhibited the largest mass specific capacitance of $337.15 \mathrm{~F} / \mathrm{g}$ at the normalised current of $0.4 \mathrm{~A} / \mathrm{g}$ which was much higher than those of $\mathrm{CNTs} / \mathrm{MnO} 2$ and $\mathrm{CNTs} / \mathrm{SnO} 2$ by $\mathrm{Ng}$ and co-workers [6]. Assuming proportional contributions from the oxide/oxides and CNTs in each of the three different nanocomposites, the values of the specific capacitance, CM- oxide(s) of the $(\mathrm{Sn}+\mathrm{Mn}) \mathrm{Ox}, \mathrm{MnO} 2$, and $\mathrm{SnO} 2$ were found to be $534.44 \mathrm{~F} / \mathrm{g}$. The resulted higher specific capacitance of nanocomposite was due to the increased surface area of the electrodes by both $\mathrm{SnO} 2$ and $\mathrm{MnO} 2$ nanoparticulates. The co-deposited $\mathrm{SnO} 2$ nanoparticulates serving as a more conductive metal oxide also enhanced the electronic conductivity of such nanocomposite by preventing the formation of thick nanolayer of $\mathrm{MnO} 2$ under acidic condition. The active site utilisation of the co-deposited oxides was much higher and the complete utilisation of those sites would be possible with the reduction of the normalised currents due to the slower rate of intercalation and deintercalation of the ions into or from the structure of the nanocomposite, resulting in more extensive mass transport processes.

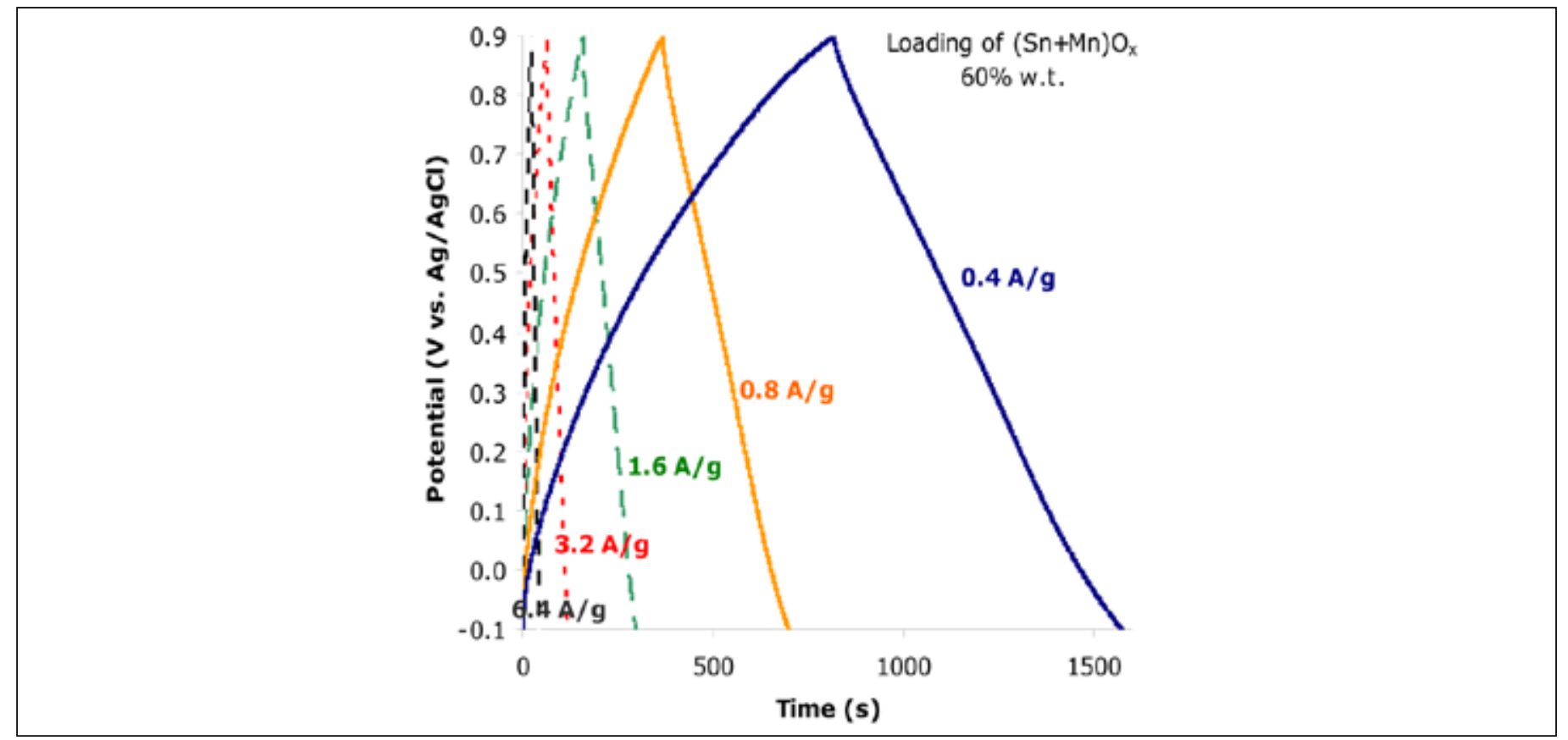

Figure 7: Potential-time plots from the galvanostatic charge-discharge test of the CNTs/(Sn+Mn)Ox $60 \%$ w.t. nanocomposites at different normalised currents $(0.4,0.8,1.6,3.2$, and $6.4 \mathrm{~A} / \mathrm{g})$ in $2.0 \mathrm{M} \mathrm{KCl}$. Mass of nanocomposites on each of the electrode: $0.10 \mathrm{mg}$. 


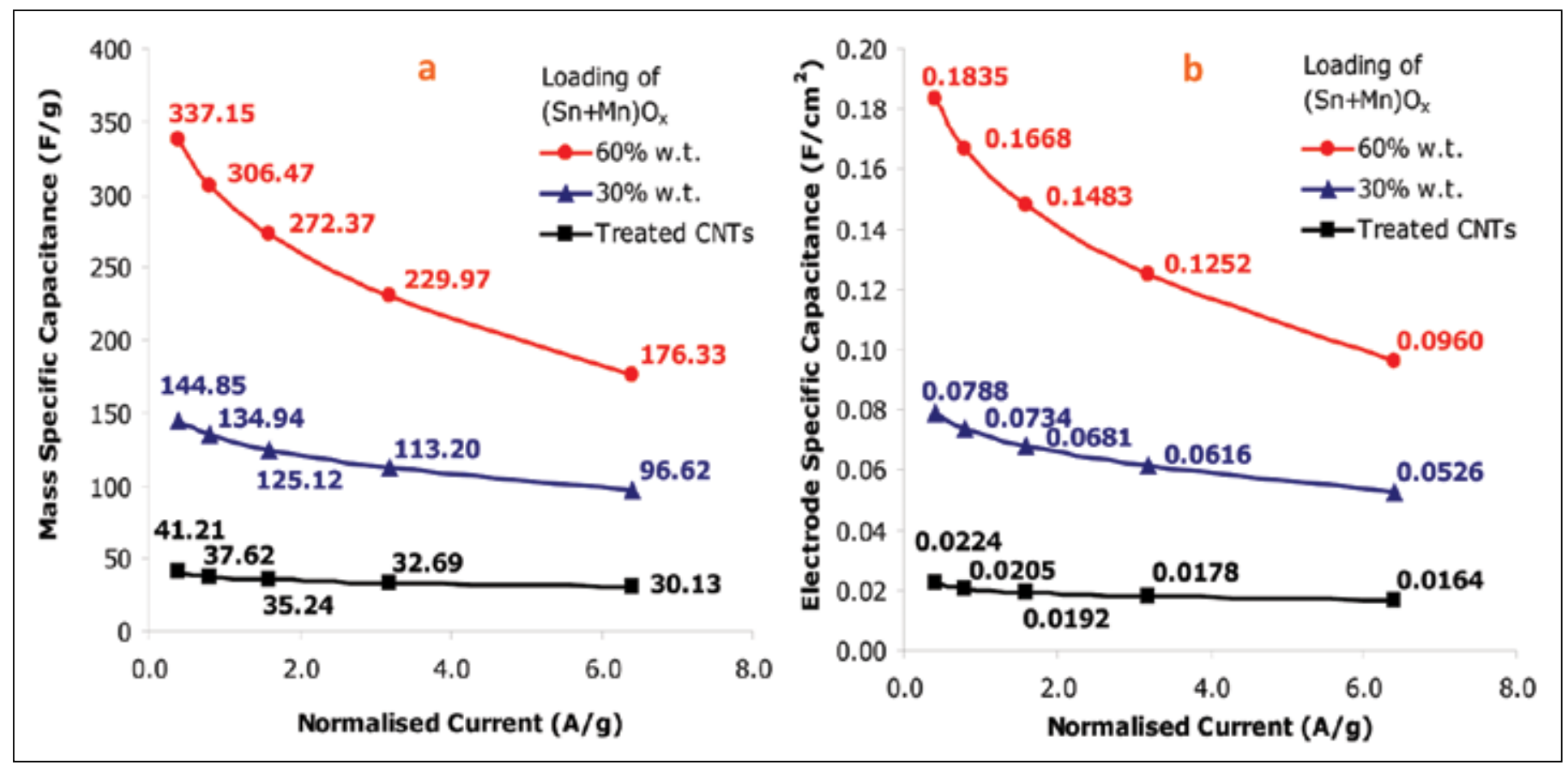

Figure 8: (a) Mass and (b) electrode specific capacitance of the CNTs/(Sn+Mn)Ox $60 \%$ w.t. nanocomposite at different charge/ discharge normalised currents $(0.4,0.8,1.6,3.2$, and $6.4 \mathrm{~A} / \mathrm{g})$. Mass of active material on each of the electrode: $0.10 \mathrm{mg}$.

The increase in specific capacitance followed an increasing rate with the decreasing normalised current and this was especially obvious in the case of the CNTs/ $(\mathrm{Sn}+\mathrm{Mn}) \mathrm{Ox} 60 \%$ w.t. nanocomposite as compared to the nanocomposite with the lower mixed-oxides loading. The acid-treated CNTs showed the smallest increase among the three materials examined, i.e. from 30.13 to 41.21 F/g when the normalised currents were decreased. The significant increase in the specific capacitance at an increasing rate at lower normalised currents especially in the case of both nanocomposites could be attributed to the porous structure of the nanocomposites and active site utilisation of the mixed-oxides. Especially when there was a high loading of the mixed-oxides, a more complete active site utilisation would be possible with the reduction of the normalised currents because of the slower rate of the intercalation or deintercalations of the ions into or from the structure of the nanocomposite, resulting in more extensive mass transport processes. At higher normalised currents the iR drop was higher due to the distribution of charges within the pores, thus the lower capacitance.

Table 1 shows the properties and the calculation of the charge-discharge of the $\mathrm{CNTs} /(\mathrm{Sn}+\mathrm{Mn}) \mathrm{Ox} 60 \%$ w.t. nanocomposite at the different normalised currents and the associated iR drops. As expected, the iR drop decreases with decreasing normalised currents applied (thus, increasing specific capacitance). Nonetheless, it should be noted that at the normalised current of $0.4 \mathrm{~A} / \mathrm{g}$, the CNTs/ $(\mathrm{Sn}+\mathrm{Mn}) \mathrm{Ox} 60 \%$ w.t. recorded an iR drop of only 9.2 $\mathrm{mV}$, which is equivalent to $0.92 \%$ of the $1.0 \mathrm{~V}$ operating potential range.

\begin{tabular}{|l|c|c|c|c|c|}
\hline \multirow{2}{*}{ Parameters } & \multicolumn{5}{c|}{ Normalised Currents (A/g) } \\
\cline { 2 - 6 } & $\mathbf{0 . 4}$ & $\mathbf{0 . 8}$ & $\mathbf{1 . 6}$ & $\mathbf{3 . 2}$ & $\mathbf{6 . 4}$ \\
\hline Charge Slope (V/s) & 0.0011 & 0.0023 & 0.0051 & 0.0116 & 0.0290 \\
\hline Discharge Slope (V/s) & -0.0013 & -0.0030 & -0.0070 & -0.0174 & -0.0484 \\
\hline Specific cap. from charge slope (F/g) & 373.27 & 346.32 & 316.14 & 275.77 & 220.33 \\
\hline Specific cap. from the discharge slope (F/g) & 301.03 & 266.61 & 228.60 & 184.18 & 132.32 \\
\hline Ave. specific cap. (F/g) & 337.15 & 306.47 & 272.37 & 229.97 & 176.33 \\
\hline $\boldsymbol{i} \boldsymbol{R}$ Drop (V) & 0.0092 & 0.0150 & 0.0296 & 0.0441 & 0.0586 \\
\hline
\end{tabular}

Table 1: The parameters measured from the potential-time curves from the galvanostatic charge-discharge test and the calculated values of the capacitance and $i R$ drop for the CNTs $/(S n+M n) O x 60 \%$ w.t. nanocomposite for the potential range from -0.1 to $0.9 \mathrm{~V}$ (vs. $\mathrm{Ag} / \mathrm{AgCl}$ ) in $2.0 \mathrm{M} \mathrm{KCl}$. Mass of the CNTs/(Sn+Mn)Ox $60 \%$ w.t. nanocomposite on the electrode: 0.10mg. 
Figure 9 shows the cyclic voltammograms and the corresponding potential dependent normalised capacitance plots of the $\mathrm{CNTs} /(\mathrm{Sn}+\mathrm{Mn}) \mathrm{Ox} 60 \%$ w.t. at different cycles, namely 3rd, 40th, 350th, and 1000th where notable changes in the specific capacitance occurred. On the whole, after 1000 cycles at $20 \mathrm{mV} / \mathrm{s}$, the CNTs/ $(\mathrm{Sn}+\mathrm{Mn}) \mathrm{Ox} 60 \%$ w.t. nanocomposite retained $95.92 \%$ of its initial capacitance. Its pseudo capacitive property of this nanocomposite was still retained even after intensive scans by showing rectangular shaped voltammogram. The results demonstrated that the long cycle life of the CNTs/ $(\mathrm{Sn}+\mathrm{Mn}) \mathrm{Ox} 60 \%$ w.t. nanocomposite which deemed the material suitable for the supercapacitor application.

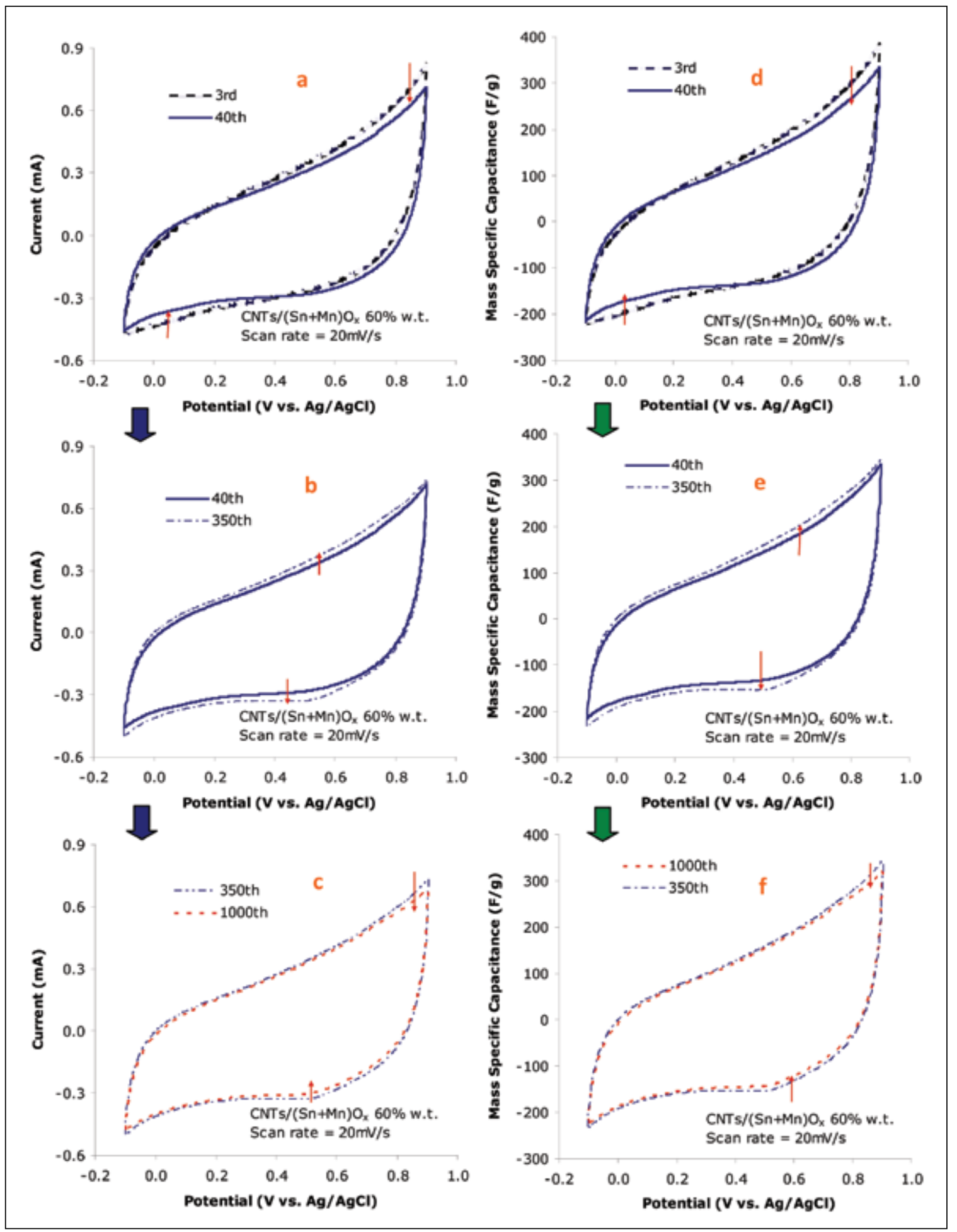

Figure 9: The changes in (a-c) cyclic voltammograms and (d-f) the corresponding normalised capacitance vs. potential (vs. Ag/ $\mathrm{AgCl})$ plots of the $3 \mathrm{rd}, 40 \mathrm{th}, 350$ th and 1000th cycle for the CNTs/(Sn+Mn)Ox 60\% w.t. nanocomposite at a scan rate of 20 $\mathrm{mV} / \mathrm{s}$ in $2.0 \mathrm{M} \mathrm{KCl}$. Mass of CNTs/(Sn+Mn)Ox 60\% w.t. on the electrode: $0.10 \mathrm{mg}$. 


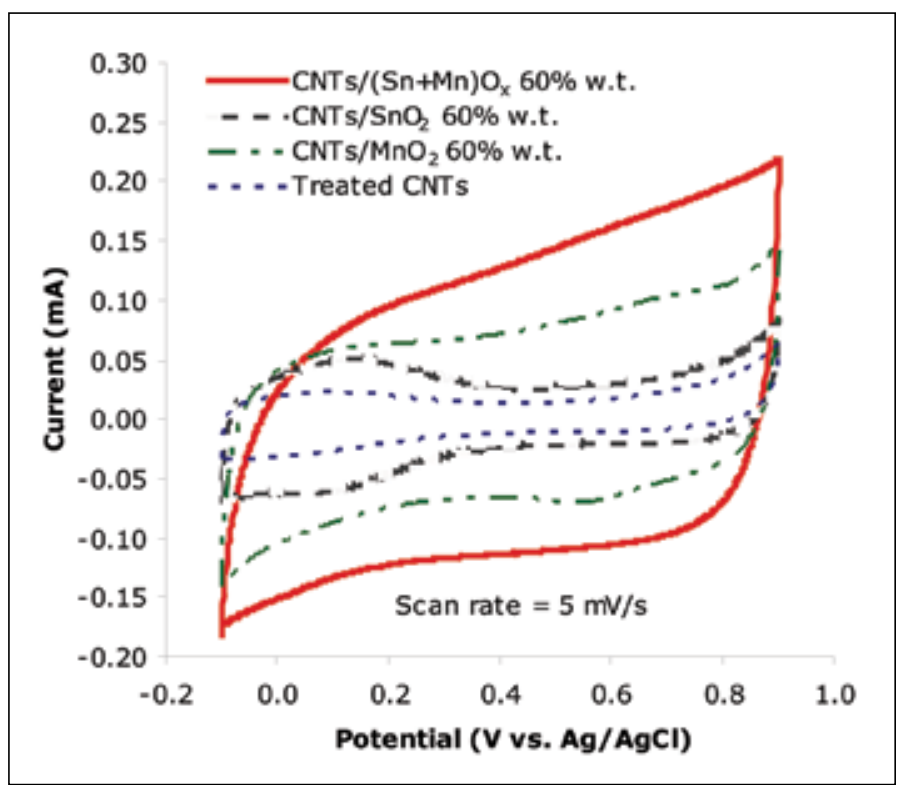

Figure 10: Cyclic voltammograms of the CNTs/(Sn+Mn)Ox $60 \%$ w.t. nanocomposite in comparison to the acid-treated CNTs, CNTs/MnO2 $60 \%$ w.t. and CNTs/SnO2 $60 \%$ w.t. nanocomposites at the scan rate of $5 \mathrm{mV} / \mathrm{s}$. Mass of active material on each of the electrode: $0.10 \mathrm{mg}$.

Figure 10 shows the cyclic voltammograms of the different nanocomposites and the acid-treated CNTs in the same potential range as that used for the $\mathrm{CNTs} /(\mathrm{Sn}+\mathrm{Mn})$ Ox $60 \%$ w.t. nanocomposite. As can be seen, the CNTs/ $(\mathrm{Sn}+\mathrm{Mn}) \mathrm{Ox} 60 \%$ w.t. nanocomposite showed larger currents on the cyclic voltammogram as compared to both $\mathrm{CNTs} / \mathrm{SnO} 260 \%$ w.t. and the $\mathrm{CNTs} / \mathrm{MnO} 260 \%$ w.t. nanocomposite indicating that the mixed-oxides possessed a synergistic effect of combining $\mathrm{MnO} 2$ and $\mathrm{SnO} 2$. To better evaluate the improvement in terms of specific

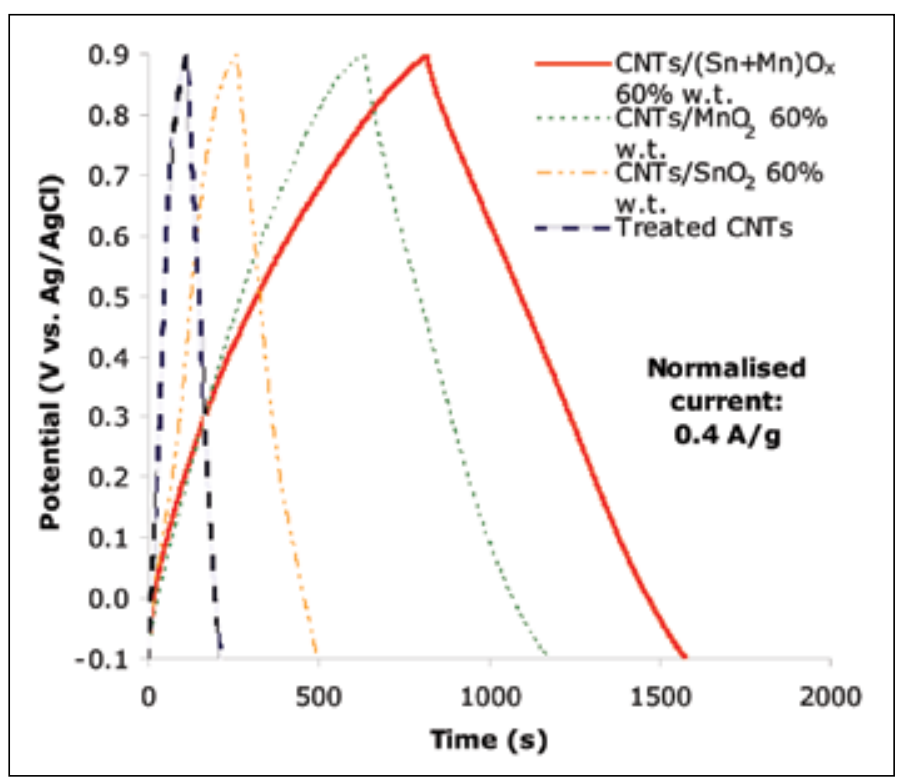

capacitance contributed by the mixed-oxides as compared to the single oxides in the different nanocomposites, the potential-time curves from the galvanostatic chargedischarge test would be used.

From the potential-time curves, it was found that the average specific capacitance values were 337.15, 236.62, 95.36, and 41.21 F/g for the CNTs/(Sn+Mn)Ox $60 \%$ w.t., CNTs/MnO2 $60 \%$ w.t., CNTs/SnO2 $60 \%$ w.t., and acid-treated CNTs respectively. Assuming proportional contributions from the oxide/oxides and CNTs in each of the three different nanocomposites, the values of the specific capacitance of the $(\mathrm{Sn}+\mathrm{Mn}) \mathrm{Ox}, \mathrm{MnO} 2$, and $\mathrm{SnO} 2$ were found to be $534.44,366.89$, and $131.46 \mathrm{~F} / \mathrm{g}$ respectively. Although the loadings of these oxides were the same in each of the nanocomposite, i.e. $60 \%$ w.t., the mixed-oxides showed an excellent improvement in terms of their specific capacitance contribution to the $\mathrm{CNTs} /(\mathrm{Sn}+\mathrm{Mn}) \mathrm{Ox}$ nanocomposite as compared to the single oxides to their respective nanocomposites. This also indicates that by combining the $\mathrm{SnO} 2$ and the $\mathrm{MnO} 2$ oxides, the effect is synergistic in terms of capacitance.

Figure 12 shows the Nyquist plots of the CNTs/ $(\mathrm{Sn}+\mathrm{Mn}) \mathrm{Ox} 30 \%$ w.t. and $60 \%$ w.t. nanocomposites in the frequency range of $10 \mathrm{mHz}$ to $100 \mathrm{kHz}$ at different biased potential (vs. $\mathrm{Ag} / \mathrm{AgCl}$ ) within the working potential range of -0.1 and $0.9 \mathrm{~V}$ as defined earlier in other electrochemical techniques. The capacitance of the nanocomposite can be derived from the linear part of the Z" vs. $1 /(2 \pi \mathrm{f})$ plots. Both Nyquist plots of the nanocomposites indicated that the maximum specific capacitance was found at a bias potential of $0.8 \mathrm{~V}$. Examining the impedance plots, the one for the CNTs/(Sn+Mn)Ox $30 \%$ w.t. nanocomposite at a bias potential of $0.8 \mathrm{~V}$ showed an almost straight line in the lower frequencies indicating ideal capacitive behaviour.

The Nyquist plots of the CNTs/(Sn+Mn)Ox $60 \%$ w.t. nanocomposite demonstrated a slight departure from the ideal straight vertical line of the capacitive behaviour

Figure 11: Potential-time curves from the galvanostatic charge-discharge test of the CNTs/(Sn+Mn)Ox 60\% w.t. nanocomposite in comparison to the acid-treated CNTs, CNTs/SnO2 60\% w.t., and CNTs/MnO2 60\% w.t., nanocomposite at the normalised current $0.4 \mathrm{~A} / \mathrm{g}$. Mass of active material on each of the electrode: $0.10 \mathrm{mg}$. 


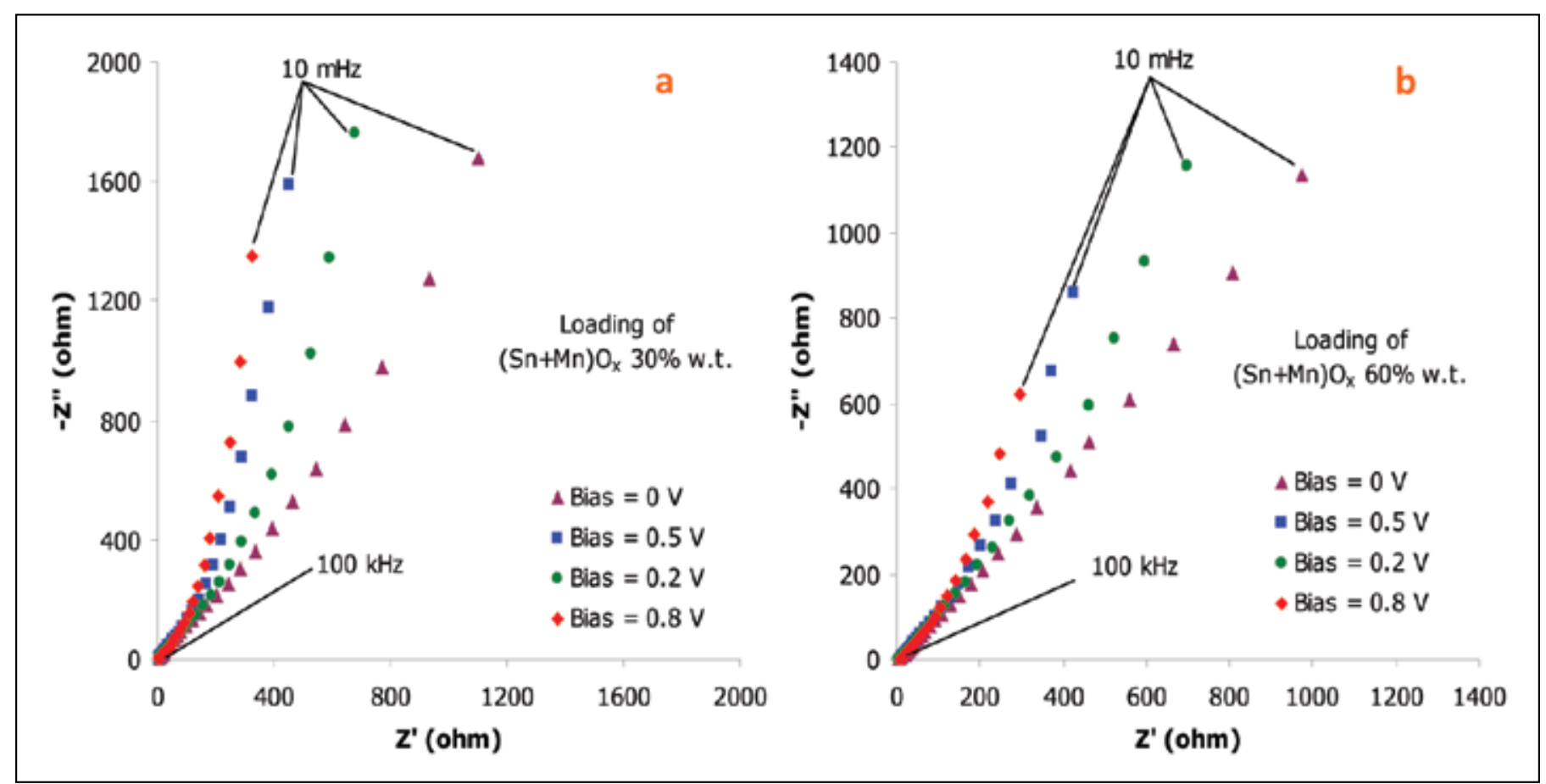

Figure 12: Complex plane impedance plots of the CNTs/(Sn+Mn)Ox (a) $30 \%$ and (b) $60 \%$ w.t. nanocomposite at various bias potentials (vs. $\mathrm{Ag} / \mathrm{AgCl}$ ) of 0, 0.2, 0.5 and $0.8 \mathrm{~V}$. Mass of nanocomposite on each of the electrode: $0.10 \mathrm{mg}$.

because of existence of a constant phase element. The delay caused by electrochemical changes especially with regards to the oxidation and reduction between the $\mathrm{Mn}$ (III) and $\mathrm{Mn}(\mathrm{IV})$ species in the working potential range and the surface adsorption of the electrolyte cation of $\mathrm{K}+$ for both oxides would cause Faradic resistance which would in turn contribute towards the deviation from the ideal $90^{\circ}$ straight line behaviour of the nanocomposite. In addition, the distributed capacitance along the inhomogeneous electrode surface and the porous structure of the nanocomposite film would have also played a part in the divergence in the ideal capacitive behaviour.

\subsection{CONCLUSION}

In conclusion, the synthesis of CNTs/(Sn+Mn)Ox $60 \%$ w.t. nanocomposite through combining the hydro-oxidation of $\mathrm{SnCl} 2$ to $\mathrm{SnO} 2$ and the reduction of $\mathrm{KMnO} 4$ to $\mathrm{MnO} 2$ was successfully achieved in a day due to the reducing presence of $\mathrm{SnCl} 2$. The acceleration of $\mathrm{MnO} 2$ deposition from 7 days to a day was caused by the acidic condition facilitated by $\mathrm{SnCl} 2$ solution. The structural destruction of CNT was observed in SEM and TEM images. However, this length reduction of CNTs was compensated with the increase in their fibril diameter by the uneven co-deposition of $\mathrm{SnO} 2$ and $\mathrm{MnO} 2$ nanoparticulates. The formation of cassiterite SnO2 (JCPDS 41-1445) and monoclinic $\mathrm{MnO} 2$ (JCPDS 42-1317) was confirmed in the determination of interplanar spacing of fringes for both metal oxides in the high resolution TEM images. This result was in accordance with the crystallinity of both metal oxides determined in XRD patterns. Electrochemically, this nanocomposite exhibited a good positive polarization at potential range of -0.1 to $0.9 \mathrm{~V}$ against $\mathrm{Ag} / \mathrm{AgCl}$. Ideal cyclic voltammogram behavior of this nanocomposite was further demonstrated by showing rectangular shape during charge-discharge process at a scan rate of $5 \mathrm{mV} / \mathrm{s}$. The highest mass specific capacitance achieved by CNTs/ (Sn+Mn)Ox $60 \%$ w.t. was $337.15 \mathrm{~F} / \mathrm{g}$ at normalised current of $0.4 \mathrm{~A} / \mathrm{g}$ which correspond to the specific capacitance (CM-oxide) of (assuming proportional contribution) $534.44 \mathrm{~F} / \mathrm{g}$. Pseudocapacitance of this nanocomposite was still retained at least $95 \%$ even after long cycle life at scan rate of $20 \mathrm{mV} / \mathrm{s}$ which deemed the material suitable for the supercapacitor application.

\subsection{REFERENCES}

[1] M. Endo, et al, High Power Electric Double Layer Capacitors (EDLC's) Form Operating Principle to Pore Size Control in Advanced Carbons, 2 Carbon Science, 2001. p117-128.

[2] Q.L.Fang, et al, Ruthenium Oxide Film Electrodes Prepared at Low Temperature for Electrochemical Capacitors. Electrochemical Society, 2001. 148J: pA833-A837. 
[3] M. Mastragostino, et al, Conducting Polymers as Electrode Materials in Supercapacitors. Solid State Ionics, 2002. 148: p493-498.

[4] D. Lozano-Castello, et al, Influence of Pore Structure and Surface Chemistry on Electric Double Layer Capacitance in Non-aqueous Electrolyte. Carbon, 2003. 41: p17651775.

[5] J.M. Boyea, R.E. Camacho, S.P. Turano and W.J. Ready, Carbon-nanotube-based supercapacitors: Technologies and Markets. Nanotechnology Law and Business, 2007. 4(1): p 585-593.

[6] $\mathrm{Ng}, \quad$ K.C., et al. CNTs/SnO2 and CNTs/MnO2 nanocomposites for the fabrication of the electrodes for supercapacitors. The Journal of the Institution of Engineers, Malaysia, 2012. 73(3): p.7-13.

[7] Kuo, S. -L. and N. -L. Wu, Electrochemical capacitor of $\mathrm{MnFe} 2 \mathrm{O} 4$ with organic Li-ion electrolyte, Electrochemical and Solid-State Letter, 2007. 10(7): p. A171-A175.

[8] Wu, M., et al., Cathodic deposition and characterization of tin oxide coatings on graphite for electrochemical supercapacitors, Journal of Power Sources, 2008. 175(1): p. 669-674.

[9] Prasad,R. K. and N. Miura, Electrochemical synthesis and characterization of nanostructured tin oxide for electrochemical redox supercapacitors, Electrochemistry Communications, 2004. 6(8): p. 849-852.

[10] Hu, Z.-A., et al., Polyaniline/SnO2 nanocomposite for supercapacitor applications. Materials Chemistry and Physics, 2009. 114(2-3): p. 990-995.

[11] Zheng, J.P., P.J. Cygan, and T.R. Jow, Hydrous Ruthenium Oxide as an Electrode Material for Electrochemical Capacitors, Journal of The Electrochemical Society, 1995. 142(8): p. 2699-2703.

[12] Zheng, J.P., Ruthenium Oxide-Carbon Composite Electrodes forElectrochemical Capacitors, Electrochemical and Solid-State Letters, 1999. 2(8): p. 359-361.

[13] Gordon, R.G., Criteria for choosing transparent conductors, MRS Bulletin, 2000. 25(8): p. 52-57.

[14] Kimbrough, R.D., Toxicity and health effects of selected organotin compounds: A review. Environ, Health Perspect, 1976. 14: p. 51-56.

[15] Kim, H.-K., et al., Characteristics of $\mathrm{RuO} 2-\mathrm{SnO} 2$ nanocrystalline-embedded amorphous electrode for thin film microsupercapacitors, Thin Solid Films, 2005. 475(12): p. 54-57.

[16] Wang, C.-C. and C.-C. Hu, Electrochemical and textural characterization of binary $\mathrm{Ru}-\mathrm{Sn}$ oxides synthesized under mild hydrothermal conditions for supercapacitors, Electrochimica Acta, 2005. 50(13): p. 2573-2581.
[17] Hu, C.-C., C.-C. Wang, and K.-H. Chang, A comparison study of the capacitive behavior for sol-gel-derived and coannealed ruthenium-tin oxide composites, Electrochimica Acta, 2007. 52(7): p. 2691-2700.

[18] Jayalakshmi, M., et al., Nano SnO2-A12O3 mixed oxide and $\mathrm{SnO} 2-\mathrm{A} 12 \mathrm{O} 3$-carbon composite oxides as new and novel electrodes for supercapacitor applications, Journal of Power Sources, 2006. 158(2): p. 1538-1543.

[19] Jayalakshmi, M., et al., Hydrothermal synthesis of SnO2V2O5 mixed oxide and electrochemical screening of carbon nano-tubes (CNT), V2O5, V2O5-CNT, and SnO2V2O5-CNT electrodes for supercapacitor applications, Journal of Power Sources, 2007. 166(2): p. 578-583.

[20] Miura, N., S. Oonishi, and K.R. Prasad, Indium Tin Oxide/ Carbon Composite Electrode Material for Electrochemical Supercapacitors, Electrochemical and Solid-State Letters, 2004. 7(8): p. A247-A249.

[21] Chabre, Y. and J. Pannetier, Structural and electrochemical properties of the proton / g-MnO2 system, Progress in Solid State Chemistry, 1995. 23(1): p. 1-130.

[22] Chang, J.-K., W.-C. Hsieh, and W.-T. Tsai, Effects of the Co content in the material characteristics and supercapacitive performance of binary Mn-Co oxide electrodes, Journal of Alloys and Compounds, 2008. 461(1-2): p. 667-674.

[23] Liu, E.-H., et al., Preparation and characterization of nanostructured $\mathrm{NiO} / \mathrm{MnO} 2$ composite electrode for electrochemical supercapacitors, Materials Research Bulletin, 2009. 44(5): p. 1122-1126.

[24] Chuang, P.-Y. and C.-C. Hu, The electrochemical characteristics of binary manganese-cobalt oxides prepared by anodic deposition, Materials Chemistry and Physics, 2005. 92(1): p. 138-145.

[25] Zhao, G.-Y., C.-L. Xu, and H.-L. Li, Highly ordered cobaltmanganese oxide (CMO) nanowire array thin film on $\mathrm{Ti} /$ Si substrate as an electrode for electrochemical capacitor, Journal of Power Sources, 2007. 163(2): p. 1132-1136.

[26] Machefaux, E., et al., Supercapacitor behavior of new substituted manganese dioxides, Journal of Power Sources, 2007. 165(2): p. 651-655.

[27] Rajendra Prasad, K. and N. Miura, Electrochemically synthesized MnO2-based mixed oxides for high performance redox supercapacitors, Electrochemistry Communications, 2004. 6(10): p. 1004-1008.

[28] Wang, S.-C., et al., Supercapacitive properties of spray pyrolyzed iron-added manganese oxide powders deposited by electrophoretic deposition technique, Thin Solid Films, 2008. 517(3): p. 1234-1238. 
[29] Lee, M.-T., et al., Annealed Mn-Fe binary oxides for supercapacitor applications, Journal of Power Sources, 2008. 185(2): p. 1550-1556.

[30] Nakayama, M., et al., Electrodeposition of manganese and molybdenum mixed oxide thin films and their charge storage properties, Langmuir, 2005. 21(13): p. 5907-5913.

[31] Nakayama, M., et al., Effects of heat-treatment on the spectroscopic and electrochemical properties of a mixed manganese/vanadium oxide film prepared by electrodeposition, Journal of Materials Research, 2004. 19(5): p. 1509-1515.

[32] Sun, L.-J., et al., Electrodeposited hybrid films of polyaniline and manganese oxide in nanofibrous structures for electrochemical supercapacitor, Electrochimica Acta, 2008. 53(7): p. 3036-3042.

[33] Sharma, R.K., A.C. Rastogi, and S.B. Desu, Manganese oxide embedded polypyrrole nanocomposites for electrochemical supercapacitor, Electrochimica Acta, 2008. 53(26): p. 7690-7695.

[34] Shlyakhtin, O.A., et al., Ni-Mn hydroxides as new high power electrode materials for supercapacitor applications, Materials Letters, 2009. 63(1): p. 109-112.

[35] Wu, N.-L., S.-L. Kuo, and M.-H.Lee, Preparation and optimization of $\mathrm{RuO} 2$-impregnated $\mathrm{SnO} 2$ xerogel supercapacitor. Journal of Power Sources, 2002. 104 (1): p 62-65.

[36] Bélanger, D., T. Brousse and J.W. Long, Manganese oxides: Battery materials make the leap to electrochemical capacitors. Electrochemical Society Interface, 2008: p 49.

[37] Glicksman, R. and C.K. Morehouse, Resistivity studies of various Leclanché cathode materials. Journal of the Electrochemical Society, 1956. 103 (3): p 149-153.

[38] Li, J., et al., A new type of $\mathrm{MnO} 2 . x H 2 O / C R F$ composite electrode for supercapacitors. Journal of Power Sources, 2006. 160 (2): p 1501-1505.

[39] Wei, J., N. Nagarajan, and I. Zhitomirsky, Manganese oxide films for electrochemical supercapacitors. Journal of Materials Processing Technology, 2007. 186 (1-3): p 356361.

[40] Jin, X., et al., Nanoscale microelectrochemical cells on carbon nanotubes. Small, 2007. 3(9): p. 1513-1517.

[41] Han, W.Q. and A. Zetti, Coating singled-walled carbon nanotubes with tin oxide. Nano Letters, 2003. 3 (5): p. 681-683.

[42] Wang, Z.G. Chen, and D. Xia, Coating of multi-walled carbon nanotube with $\mathrm{SnO} 2$ films of controlled thickness and its application for Li-ion battery, Journal of Power Sources, 2008. 184 (2): p. 432-436.
[43] Lee, H.Y. and J.B. Goodenough, Supercapacitor behavior with $\mathrm{KCl}$ electrolyte. Journal of Solid State Chemistry, 1999. 144(1): p. 220-223.

[44] Wu, N.L., C.Y. Han, and S.L. Kuo, Enhanced performance of $\mathrm{SnO} 2$ xerogel electrochemical capacitor prepared by novel crystallization process. Journal of Power Sources, 2002. 109(2): p. 418-421.

[45] Pang, S.-C., M.A. Anderson, and T.W. Chapman, Novel electrode materials for thin-film ultracapacitors: Comparison of electrochemical properties of sol-gelderived and electrodeposited manganese dioxide. Journal of The Electrochemical Society, 2000. 147(2): p. 444-450.

[46] Toupin, M., T. Brousse, and D. Belanger, Charge storage mechanism of $\mathrm{MnO} 2$ electrode used in aqueous electrochemical capacitor. Chemistry of Materials, 2004. 16(16): p. 3184-3190.

[47] Pourbaix, M., Atlas of electrochemical equilibria in aqueous solutions. 1966, Pergamon Press, New York.

[48] Chang, K.-H. and C.-C. Hu, Oxidative synthesis of $\mathrm{RuOx} \cdot \mathrm{nH} 2 \mathrm{O}$ with ideal capacitive characteristics for supercapacitors. Journal of The Electrochemical Society, 2004. 151(7): p. A958-A964.

[49] Gujar, T.P., et al., Electrosynthesis of Bi2O3 thin films and their use in electrochemical supercapacitors. Journal of Power Sources, 2006. 161(2): p. 1479-1485.

[50] Gujar, T.P., et al., Electrochemically deposited nanograin ruthenium oxide as a pseudocapacitive electrode. International Journal of Electrochemical Science, 2007. 2: p. 666-673. 


\section{PROFILES}

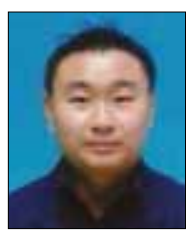

IR. DR. NG KOK CHIANG graduated from the University of Western Australia with first class honours in Bachelor of Engineering in Electrical \& Electronics and Bachelor of Commerce majoring in Accounting, Investment Finance (Derivatives), and Managerial Accounting. He then furthered his studies to the University of Nottingham, UK and graduated with a $\mathrm{PhD}$ in Engineering having worked in the area of renewable energy and its storage for three and a half years. Ir. Dr. Ng Kok Chiang in his course of research and work had liaised with various organisations such as E.ON (Power and Gas), Lockheed Martin, Jaguar/Land Rover (supercapacitors in automotive industry/electric cars), Battelle (lab management and commercialisation), Malaysia Rubber Board (energy management, artificial intelligent, control, and electronics), and MOSTI (Fabrication of Advanced Supercapacitors). He is currently the Chief Technology Officer of MyBig Sdn. Bhd. and a Professional Engineer with the R\&D Centre at Leong Hing Sdn. Bhd. involved in research and prototyping projects in collaboration with various Malaysian Government Agencies and research bodies. Among the prominent solutions founded were the advanced switching mechanism in the Nexcap storage to efficiently capture minuscule trickle of charges, intelligent control systems incorporating power electronics device, and the advanced Sunopy solar system. Ir. Dr. Ng Kok Chiang is also a certified Green Building Facilitator and a Professional Member of the Malaysia Green Building Confederation. He is currently serving as one of the committee in the Electrical Engineering Technical Division and the Secretary/Treasurer of the Consulting Engineering Special Interest Group at the Institution of Engineers, Malaysia.

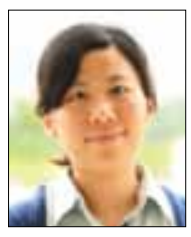

MS. SIEW SHEE LIM obtained her BSc and MEng in Chemical Engineering at University at Buffalo, New York (USA) in 2004 and 2005 respectively. After her attainment of MEng degree, she worked as an Assistant Professor in University of Nottingham Malaysia Campus since 2006. She managed to secure a MOSTI eScience Fund in 2007 and worked on the synthesis of nanoscaffolds for bone regeneration. She successfully completed this eScience Project in 2009 and is currently working her part time PHD study on the fabrication and functionalisation of nanocomposite scaffolds using cost effective bioactive compounds. She is co-author of 2 scientific, 1 education journal papers and a few others in the pipeline.

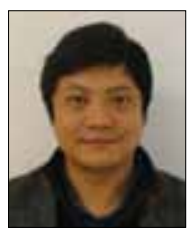

DR. CHUANG PENG did his BEng in China before coming to the UK in 2003. After obtaining his MSc (2004) and $\mathrm{PhD}$ (2007) in Environmental Engineering and Chemical Engineering respectively, he worked as a research associate for another three years in the University of Nottingham. Dr. Peng is specialised in materials electrochemistry, particularly, the development of supercapacitors for energy storage with high power demands. This includes the synthesis and characterisation of new electrode materials, and the design, testing and optimisation of supercapacitor units and high voltage stacks. Dr. Peng has also undertaken researches on photo-electro-catalysis and electro-Fenton process for decontamination of water. He is the author/co-author of 16 scientific journal papers, with accumulated citations in excess of 260. After joining the CSM in September 2011, Chuang has broadened his research interests to include various applications of materials electrochemistry in renewable energy and environmental technologies. 